Supporting material for:

\title{
Ratiometric Array of Conjugated Polymers-Fluorescent Protein Provides a Robust Mammalian Cell Sensor
}

Subinoy Rana, ${ }^{1,2, *}$ S. Gokhan Elci, ${ }^{1}$ Rubul Mout, ${ }^{1}$ Arvind K. Singla,${ }^{3}$ Mahdieh Yazdani, ${ }^{1}$ Markus Bender, ${ }^{4}$ Avinash Bajaj, ${ }^{1,5}$ Krishnendu Saha, ${ }^{1}$ Uwe H. F. Bunz, ${ }^{4}$ Frank R. Jirik, ${ }^{3}$ and Vincent M. Rotello ${ }^{1, *}$

${ }^{1}$ Department of Chemistry, University of Massachusetts Amherst, 710 North Pleasant Street, Amherst, MA 01003, USA. ${ }^{2}$ Department of Materials, Imperial College London, Prince Consort Road, London SW7 2AZ, United Kingdom. ${ }^{3}$ Department of Biochemistry and Molecular Biology, The McCaig Institute for Bone and Joint Health, Arnie Charbonneau Cancer Institute, University of Calgary, Calgary, Alberta, Canada. ${ }^{4}$ Organisch-Chemisches Institut, Ruprecht-Karls-Universität Heidelberg, Im Neuenheimer Feld 270, 69120 Heidelberg, FRG. ${ }^{5}$ Laboratory of Nanotechnology and Chemical Biology, Regional Centre for Biotechnology, 180 Udyog Vihar, Phase I, Gurgaon122016, Haryana, India. 


\section{Table of Contents}

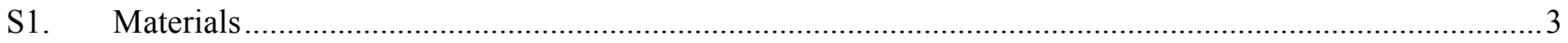

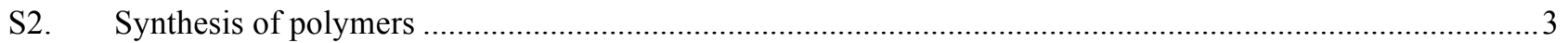

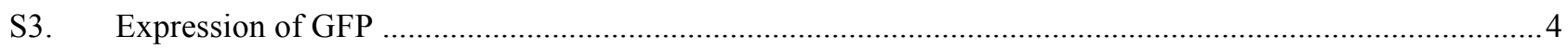

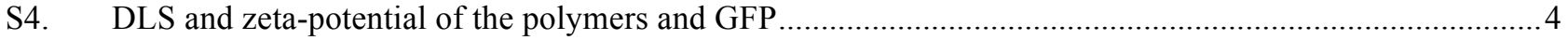

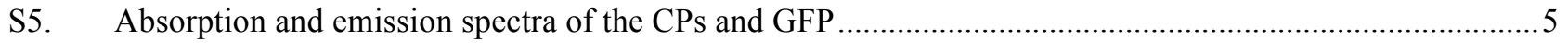

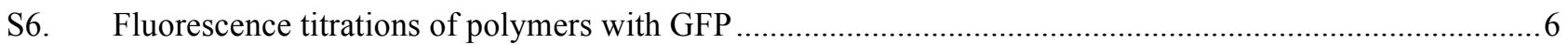

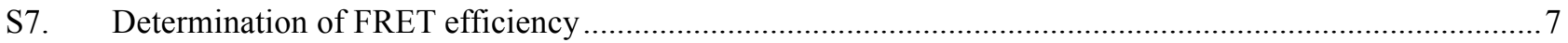

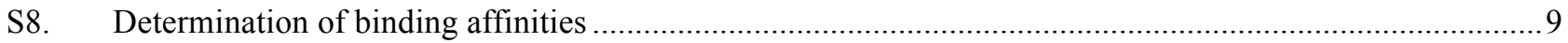

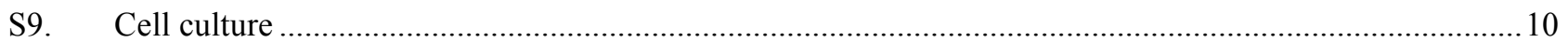

S10. Cell concentration-dependent FRET responses ................................................................................ 11

S11. Aggregation behavior of polymer on cell surfaces …........................................................................ 11

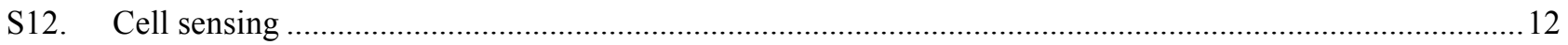

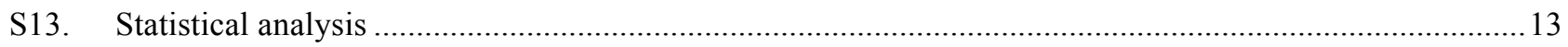

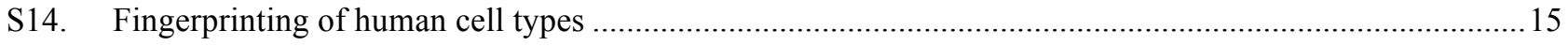

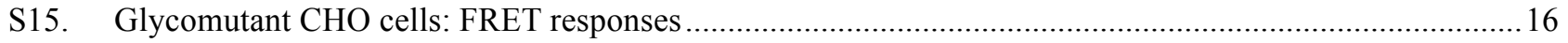

S16. Contribution of CPs towards the differential FRET responses ….............................................................. 16

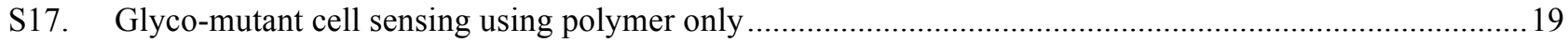

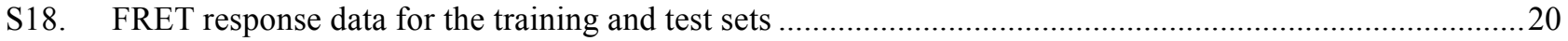

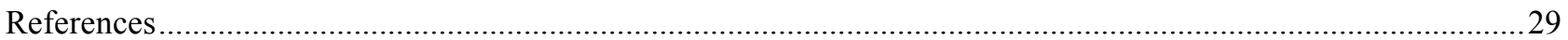




\section{S1. Materials}

All chemicals and solvents for syntheses were purchased from Fisher Scientific and Sigma-Aldrich, and used without further purification, unless otherwise stated. CD $\beta$ Geo, pTD and V14 cell lines were developed and donated by Prof. D. J. Jerry. The NT2/D1 cell line was donated by Prof. R. T. Zoeller. The three Sublines with organ-specific metastatic signatures were developed as described in the following sections. All other cell lines were purchased from American Type Culture Collection (ATCC) and were maintained according to the recommended guidelines. Five to six week old athymic $(n u / n u)$, beige (NIH-III) female mice were purchased from Charles River Laboratories (St-Constant, QC). Mice were housed in viral antibody-free conditions in the University of Calgary Animal Resources Center. All experiments were conducted in compliance with Canadian Council of Animal Care guidelines and with ethical approval from the University of Calgary Animal Care Committee.

\section{S2. Synthesis of polymers}

Polymer P1 and P5 were synthesized as described in earlier reports. ${ }^{1,2,3} \mathbf{P 2}, \mathbf{P} 3$ and $\mathbf{P 4}$ polymers were synthesized from previously reported precursors ${ }^{4,5}$ and prepared through reaction with iodomethane. ${ }^{6}$

Table S1. Structural parameters of the polymers used in the present study.

\begin{tabular}{ccccc}
\hline Polymers & $\mathbf{M}_{\mathbf{n}}$ & $\mathbf{M}_{\mathbf{w}}$ & $\mathbf{P D I}$ & $\mathbf{n}$ \\
\hline P1 & 5,023 & 10,246 & 2.01 & 12 \\
P2 & 10,840 & 21,029 & 1.90 & 15 \\
P3 & 49,503 & 103,956 & 2.10 & 40 \\
P4 & 9,445 & 23,335 & 1.26 & 9 \\
P5 & 3,500 & 6,600 & 1.88 & 12 \\
\hline
\end{tabular}

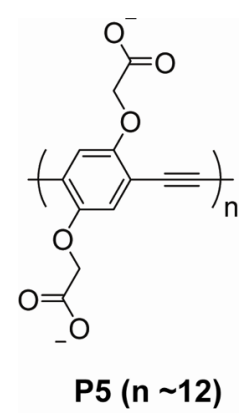

Figure S1. Structure of polymer P5, the anionic polymer used as the negative control. 


\section{S3. Expression of GFP}

Starter cultures from a glycerol stock of GFP [enhanced GFP (eGFP) cloned into the pET21d vector (Novagen) where 6-His tag was located at $N$-terminal] in BL21(DE3) E. coli host was grown overnight in $50 \mathrm{~mL}$ of $2 \times$ YT media with $50 \mu \mathrm{L}$ of $1000 \times$ ampicillin $(16 \mathrm{~g}$ tryptone, $10 \mathrm{~g}$ yeast extract, $5 \mathrm{~g} \mathrm{NaCl}$ in $1 \mathrm{~L}$ water). The cultures were shaken overnight at $250 \mathrm{rpm}$ at $37{ }^{\circ} \mathrm{C}$. The following day, $10 \mathrm{~mL}$ of the culture were inoculated in $1 \mathrm{~L}$ of $2 \times$ YT containing $1 \mathrm{~mL} 1000 \times$ ampicillin and shaken until $\mathrm{OD}_{600}=0.7$ was reached. This culture was then induced by adding isopropyl- $\beta$-Dthiogalactopyranoside (IPTG; $1 \mathrm{mM}$ ) and shaken at $28{ }^{\circ} \mathrm{C}$. After $3 \mathrm{~h}$, the cells were harvested by centrifugation (5000 rpm for $15 \mathrm{~min}$ ) and lyzed in lysis buffer ( $2 \mathrm{mM}$ imidazole, $50 \mathrm{mM} \mathrm{NaH}_{2} \mathrm{PO}_{4}$, $0.3 \mathrm{M} \mathrm{NaCl}$ ) using a microfluidizer. Once lyzed, the solution was centrifuged at 15,000 rpm for 45 min at $4{ }^{\circ} \mathrm{C}$. The supernatant was further purified using HisPur Cobalt-NTA columns (Pierce, cat. \# 89969). The imidazole was removed by dialyzing in $5 \mathrm{mM}$ sodium phosphate buffer $(\mathrm{pH}=7.4)$. The purity of the protein was verified by gel electrophoresis, absorption and emission spectra.

\section{S4. DLS and zeta-potential of the polymers and GFP}

The hydrodynamic diameter and zeta potential of the CPs and GFP were measured in $5 \mathrm{mM}$ phosphate buffer ( $\mathrm{pH}=7.4)$ using Malvern ZetasizerNano ZS instrument. Each experiment was repeated three times and the average \pm SD values are presented in the table below.

Table S2. Size and net charge of the polymers and GFP

\begin{tabular}{|ccc|}
\hline Polymer/protein & Size $(\mathbf{n m})$ & Zeta potential $(\mathbf{m V})$ \\
\hline P1 & $164 \pm 3$ & $+(6.5 \pm 1)$ \\
P2 & $183 \pm 16$ & $+(7.1 \pm 0.8)$ \\
P3 & $310 \pm 32$ & $+(8.0 \pm 0.9)$ \\
P4 & $245 \pm 13$ & $+(5.9 \pm 1.1)$ \\
P5 & $253 \pm 9$ & $-(16.0 \pm 1.9)$ \\
GFP & $10 \pm 2$ & $-(7.5 \pm 1.1)$ \\
\hline
\end{tabular}




\section{S5. Absorption and emission spectra of the CPs and GFP}

Absorbance spectra were measured in a spectrophotometer. Emission spectra were recorded in Molecular Devices Spectramax M5 plate reader at an excitation of $430 \mathrm{~nm}$.
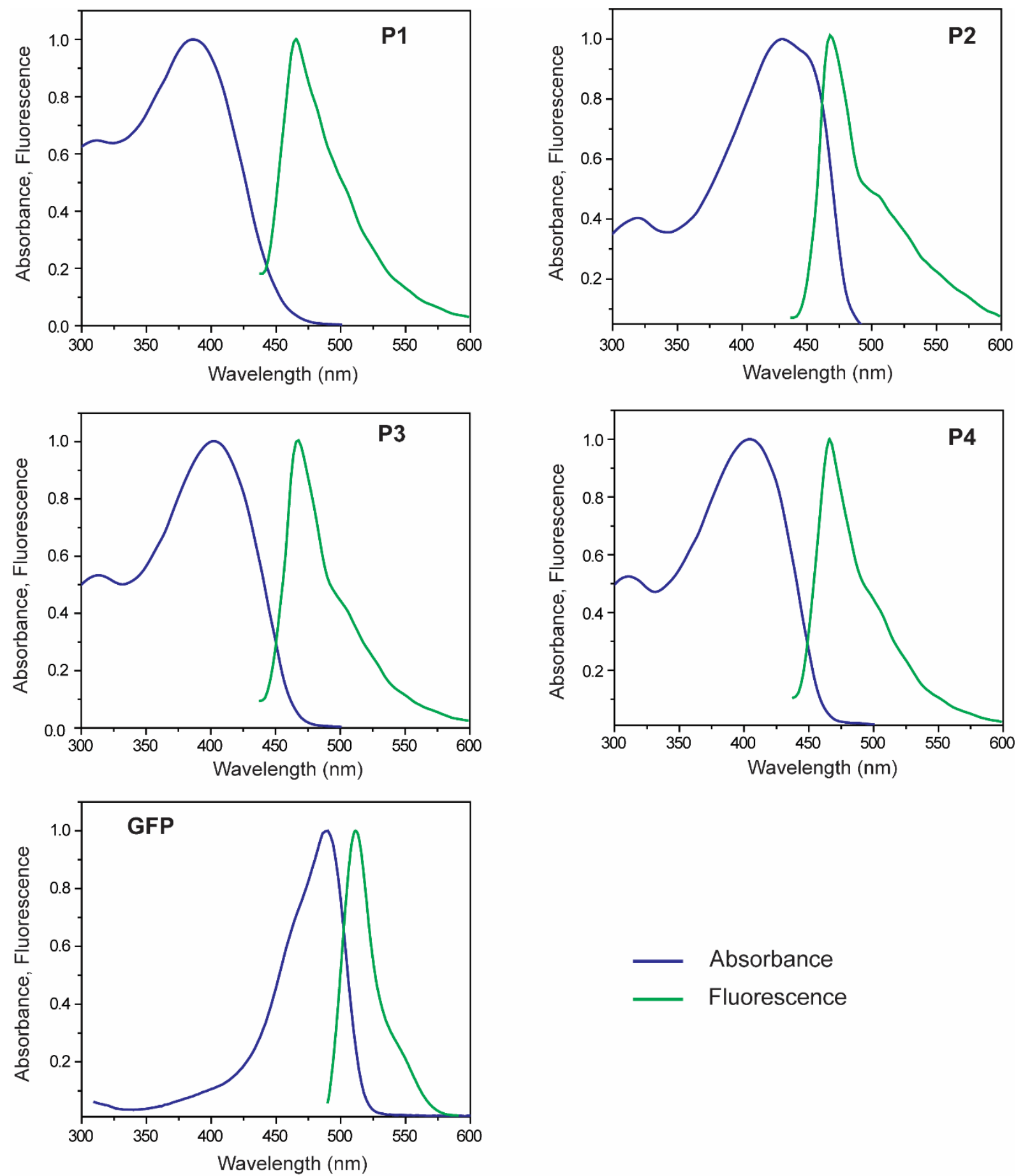

Absorbance

Fluorescence

Figure S2. Normalized absorption and emission spectra of the CPs and GFP in $5 \mathrm{mM}$ sodium phosphate buffer (pH 7.4). 


\section{S6. Fluorescence titrations of polymers with GFP}

Fluorescence titration of the CPs (P1-P5) with GFP were carried out in a Molecular Devices Spectramax M5 plate reader. Different concentration of GFP was incubated with the CPs in black 96well microplates (Costar) for 30 minutes at room temperature followed by recording the fluorescence spectra with an excitation wavelength of $430 \mathrm{~nm}$. A cut-off of $455 \mathrm{~nm}$ was applied. The final concentration of GFP was $200 \mathrm{nM}$ and that of P1-P5 were between 8 to $300 \mathrm{nM}$. For the energy transfer studies, optimal concentrations of polymer and GFP complexes selected were P1: $300 \mathrm{nM}$, P2: $150 \mathrm{nM}$, P3: $8 \mathrm{nM}$, NP4: $50 \mathrm{nM}$ (based on their molecular weights). We used P5 (100 nM) as the negative control.
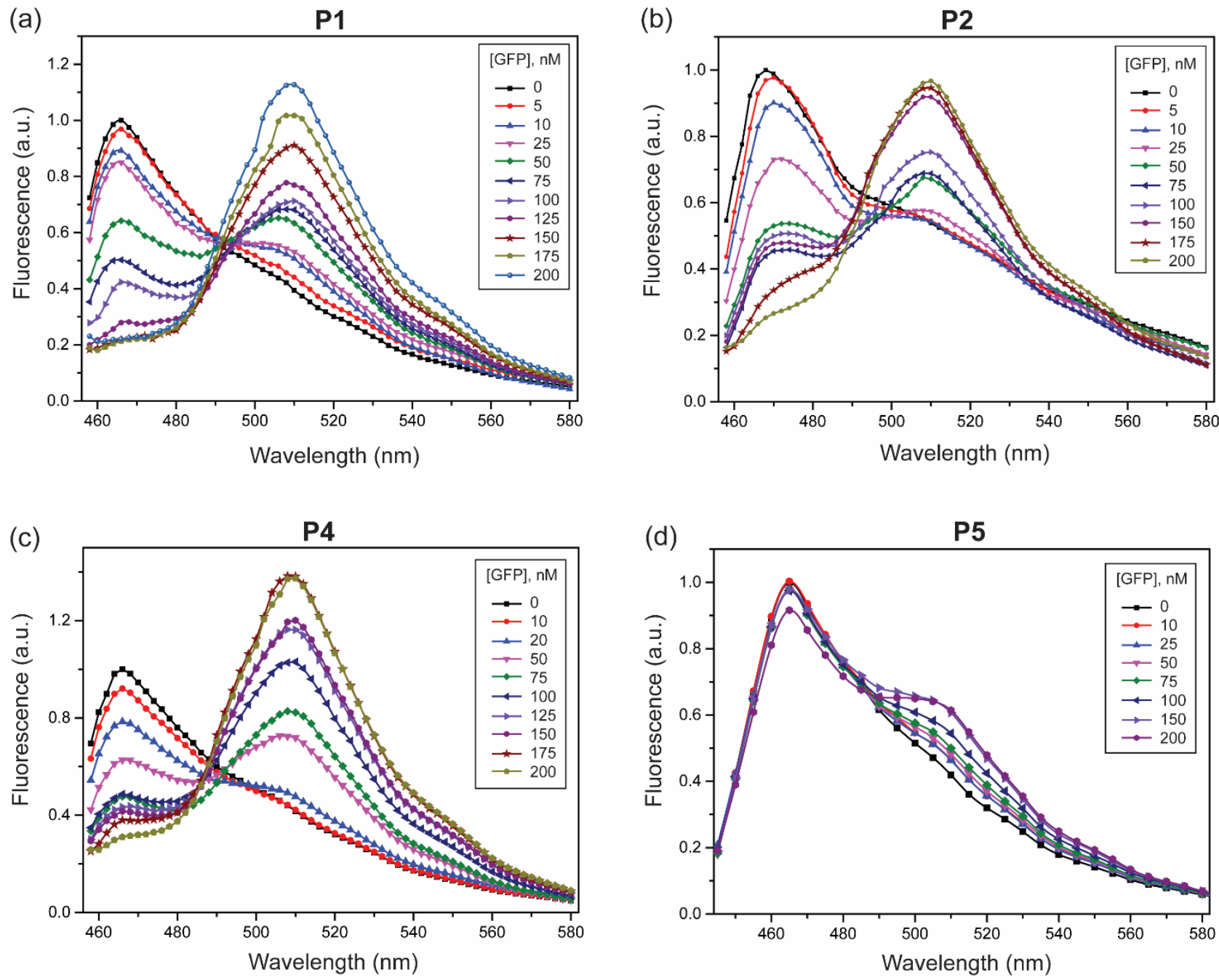

Figure S3. Emission spectra as a function of GFP concentration for the (a) P1-GFP, (b) P2-GFP, (c) P4GFP and (d) P5-GFP pair. Spectra were recorded at an excitation of $430 \mathrm{~nm}$ following incubation of CPs and GFP in $5 \mathrm{mM}$ sodium phosphate buffer ( $\mathrm{pH} 7.4)$. 


\section{S7. Determination of FRET efficiency}

We utilized the following equation ${ }^{7}$ to calculate the experimental energy transfer efficiency $(E)$ :

$$
E=\frac{\left(I_{\mathrm{CP}}-I_{\mathrm{CP}-\mathrm{GFP}}\right)}{I_{\mathrm{CP}}}
$$

where $I_{\mathrm{CP}}$ and $I_{\mathrm{CP}-\mathrm{GFP}}$ are the fluorescence intensities of the $\mathrm{CP}$ donor alone and the $\mathrm{CP}$ in the presence of GFP acceptor, respectively.

Estimates of the CP-GFP separation distance $R$ were calculated using the Förster formalism by fitting the above experimental FRET efficiencies $E$ using the expression ${ }^{8}$ :

$$
R=\left(\frac{n(1-E)}{E}\right)^{1 / 6} R_{0}
$$

where $n$ is the number of GFP attached to the same polymer, $R$ is the donor-acceptor separation, and $R_{0}$ is the Förster distance designating the donor-acceptor separation at $50 \%$ energy transfer efficiency. The Förster distance $R_{0}$ is determined from the equation ${ }^{9}$ :

$$
R_{0}=9.78 \times 10^{3}\left[\kappa^{2} \eta^{-4} Q_{\mathrm{CP}} J(\lambda)\right]^{1 / 6}
$$

where $\eta$ is the refractive index of the medium, $Q_{\mathrm{CP}}$ is the polymer quantum yield in the absence of acceptor, $J(\lambda)$ is the spectral overlap integral, and $\kappa^{2}$ is the dipole orientation factor. We used $\kappa^{2}=2 / 3$ corresponding to a random dipole orientation, ${ }^{10}$ based on the assumption that in a polymer-protein pair it is impossible to control the relative orientation of the dipoles.

Figure S4 shows the data fitted as a function of $n$ using the above expressions, and Table S3 lists the parameters determined for the various CP-GFP pairs.

Table S3. The data summary of spectral overlap integral $(J)$, maximum energy transfer efficiency $\left(E_{\max }\right)$, Förster distance $\left(R_{0}\right)$ and donor-acceptor distance $(R)$.

\begin{tabular}{|ccccc|}
\hline Polymer & $\boldsymbol{J}\left(\mathbf{M}^{-\mathbf{1}} \mathbf{c m}^{-\mathbf{1}} \mathbf{n m}^{\mathbf{4}}\right)$ & $\boldsymbol{R}_{\mathbf{0}}(\AA)$ & $\boldsymbol{E}_{\mathbf{m a x}}(\mathbf{\%})$ & $\boldsymbol{R}(\AA)$ \\
\hline P1 & $1.81 \times 10^{15}$ & 37.45 & 78 & 29.51 \\
$\mathbf{P 2}$ & $1.57 \times 10^{15}$ & 43.40 & 70 & 38.24 \\
$\mathbf{P 3}$ & $1.84 \times 10^{15}$ & 35.38 & 72 & 51.40 \\
$\mathbf{P 4}$ & $1.92 \times 10^{15}$ & 47.37 & 60 & 53.41 \\
\hline
\end{tabular}

The orientation factor $\kappa^{2}=2 / 3$ was used to calculate the $R_{0}$. Here, $R$ values were obtained from fitting the data of FRET efficiency against CP to GFP ratio. 

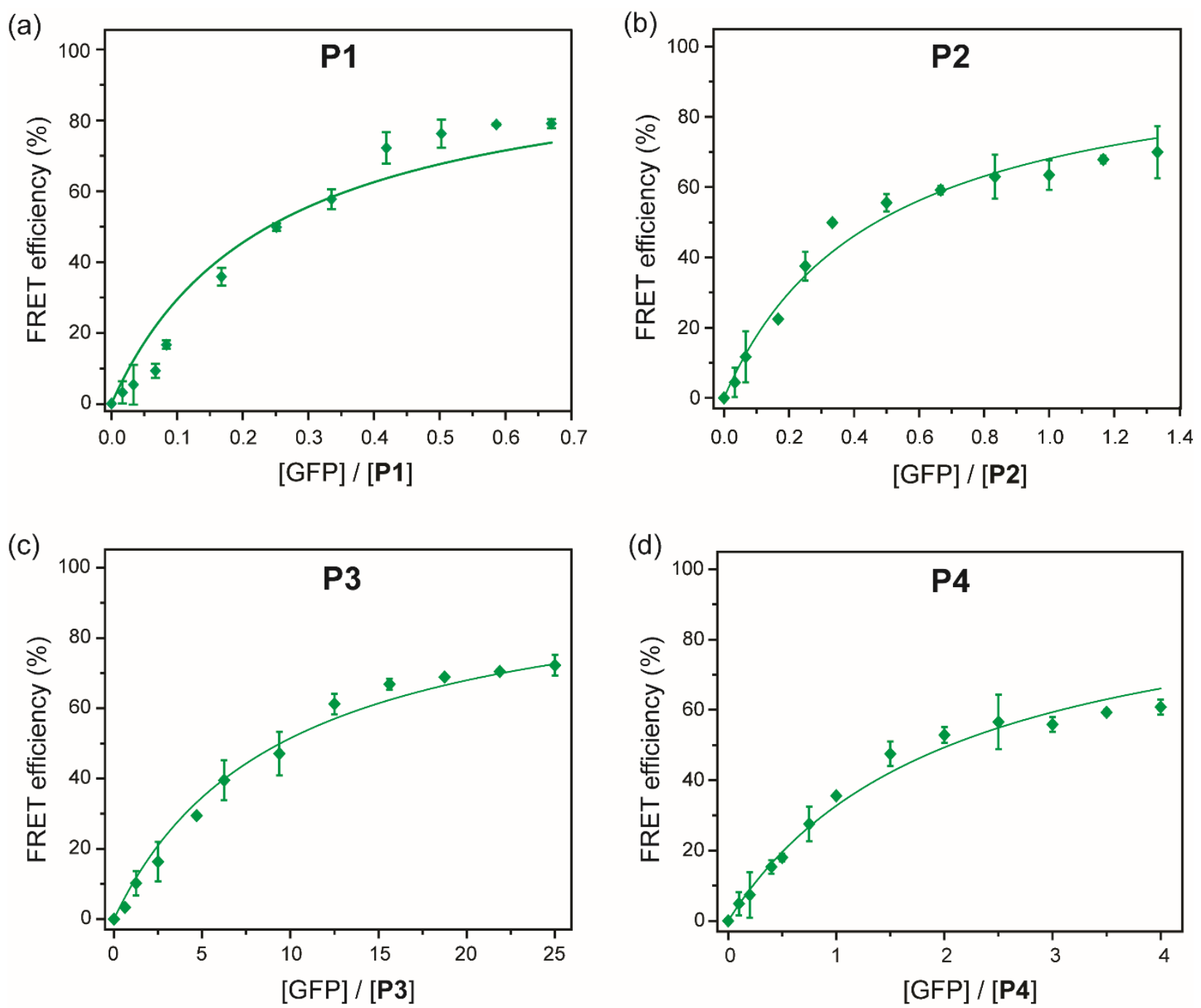

Figure S4. FRET efficiency (green squares) as a function of the increasing GFP concentration for (a) P1, (b) P2, (c) P3, and (d) P4. Each value is the average of three independent measurements and the error bars are the \pm standard deviations (SD). Solid lines represent the best fitted curves obtained through fitting the Förster equation. 


\section{S8. Determination of binding affinities}

Titration of CP by GFP results in FRET and the resulting fluorescence decay of CP as a function of GFP concentration was fitted to one-site binding equation, ${ }^{11}$ which is:

$$
I=I_{0}+\frac{\alpha}{2}\left([\mathrm{P}]_{0}+n[\mathrm{~A}]+\frac{1}{K_{\mathrm{s}}}\right)-\sqrt{\left\{\left([\mathrm{P}]_{0}+n[\mathrm{~A}]+\frac{1}{K_{\mathrm{s}}}\right)^{2}-4 n[\mathrm{P}]_{0}[\mathrm{~A}]\right\}}
$$

where, $I_{0}$ is the fluorescence intensity of a $\mathrm{CP}$ at a concentration $[\mathrm{P}]_{0}$ in the absence of acceptor (GFP), $I$ is the fluorescence intensity of the $\mathrm{CP}$ in the presence of a concentration [A] of GFP, and $n$ denotes the CP to GFP binding ratio, i.e. how many sites the GFP has to quench multiple PPE chains. The term $\alpha$ is the correlation factor between the fluorescence intensities and concentrations of the donor and acceptor species. This factor is constant if the instrumental variables (e.g. slit width, excitation wavelength, sensitivity, etc.) and the polymer and GFP identities are fixed.
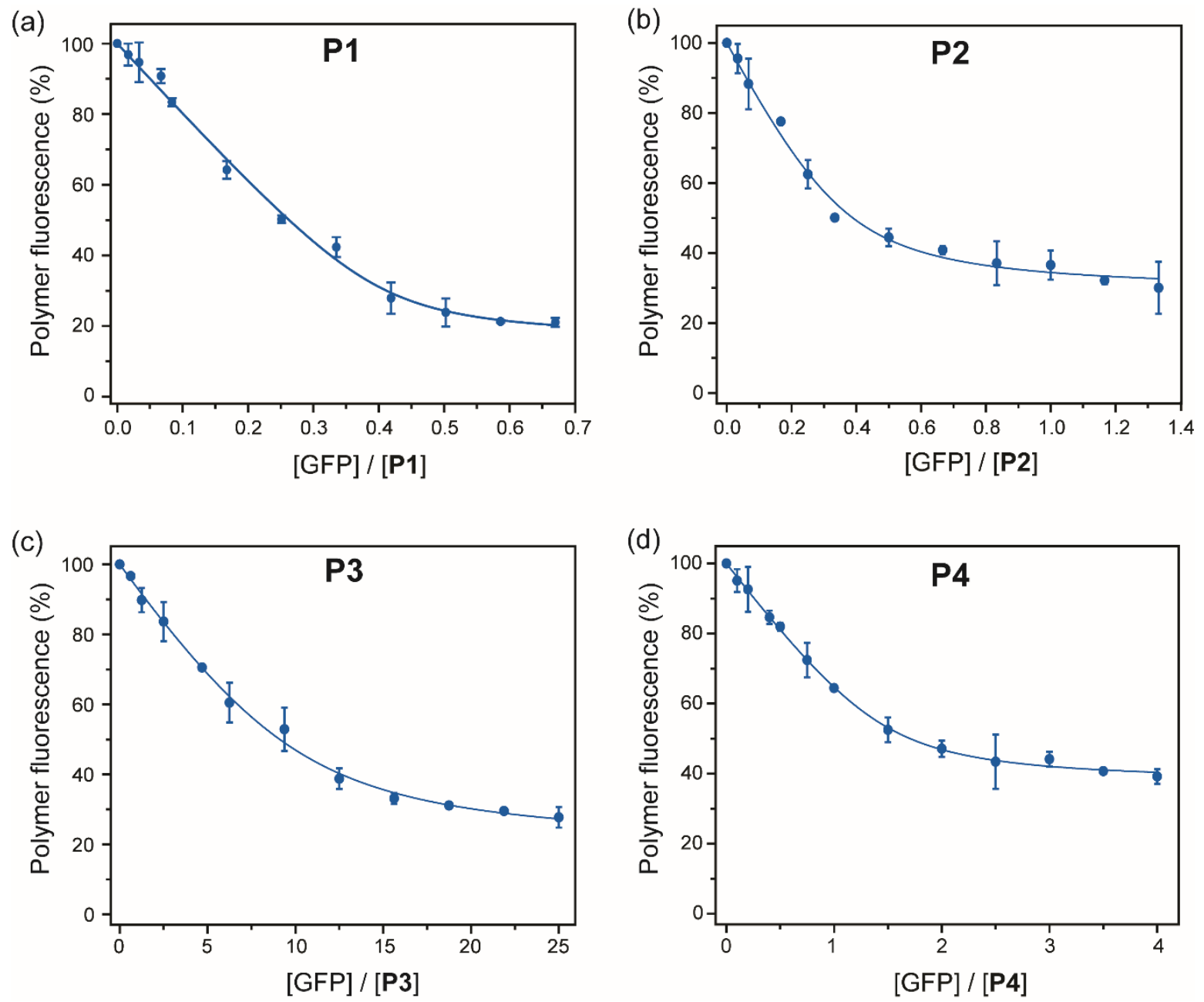

Figure S5. Quenching of CP fluorescence (blue circles) as a function of the increasing GFP concentration for (a) P1, (b) P2, (c) P3, and (d) P4. Each value is the average of three independent 
measurements and the error bars are the \pm SD. Solid lines represent the best fitted curves, obtained from fitting the binding equation using the model of single set of identical binding sites.

Table S4: CP-GFP complex stability constant $\left(K_{s}\right)$ and CP to GFP binding stoichiometry $(n)$ determined from fitting the fluorescence titration data

\begin{tabular}{|ccc|}
\hline Polymers & $\boldsymbol{K}_{\mathbf{s}}\left(\mathbf{M}^{\mathbf{- 1}}\right)$ & Binding ratio $(\boldsymbol{n})$ \\
\hline P1 & $9.13 \times 10^{7}$ & 2.5 \\
P2 & $4.11 \times 10^{7}$ & 2.8 \\
P3 & $6.78 \times 10^{8}$ & 0.1 \\
P4 & $2.10 \times 10^{8}$ & 0.7 \\
\hline
\end{tabular}

\section{S9. Cell culture}

All the cells were cultured at $37{ }^{\circ} \mathrm{C}$ under a humidified atmosphere containing $5 \% \mathrm{CO}_{2}$. Cells were regularly passaged by trypsinization with $0.25 \%$ trypsin-EDTA $1 \times$ solution (Invitrogen) in PBS $(\mathrm{pH}$ 7.4). HeLa, HepG2, MCF7, and NT2/D1 cells were cultured in DMEM media supplemented with $10 \%$ fetal bovine serum (FBS) and 1\% antibiotics (Cellgro, 30-004-CI) in T75 flasks. CD $\beta$ Geo, pTD, V14, and MCF10A cells were grown in DMEM-F12 media supplemented with 2\% adult bovine serum (ABS), $25 \mathrm{mM}$ HEPES, $10 \mathrm{mg} / \mathrm{mL}$ insulin, $5 \mathrm{ng} / \mathrm{mL}$ epidermal growth factor (EGF) and 15 $\mathrm{mg} / \mathrm{mL}$ gentamicin. The NCI-H1299 (parental), and the Sublines were grown in RPMI-1640 media supplemented with 10\% FBS and 1\% antibiotic solution. CHO-K1, pgsB-618, pgsA-745, and pgsD677 cells were cultured in Ham's nutrient mixture F12 supplemented with 10\% FBS and 1\% antibiotic solution (Cellgro, 30-004-CI).

Cells grown at $\sim 80 \%$ confluence in the T75 flasks were washed twice with DPBS buffer (Thermo Scientific, SH30028.02), trypsinized, and collected in the respective growth medium. Thereafter, cells were spun down, resuspended in the medium (without serum/antibiotics), and counted using a hemocytometer. With appropriate dilutions the suspensions were used in the following cell sensing assays. 


\section{S10. Cell concentration-dependent FRET responses}

The quantitative behavior of the sensor in cell sensing was determined in the same manner as the sensing studies. Cells were counted by a hemocytometer in triplicates and then serially diluted in the corresponding media. Fluorescence change was measured after 30 mins of incubation with the cells.

(a)

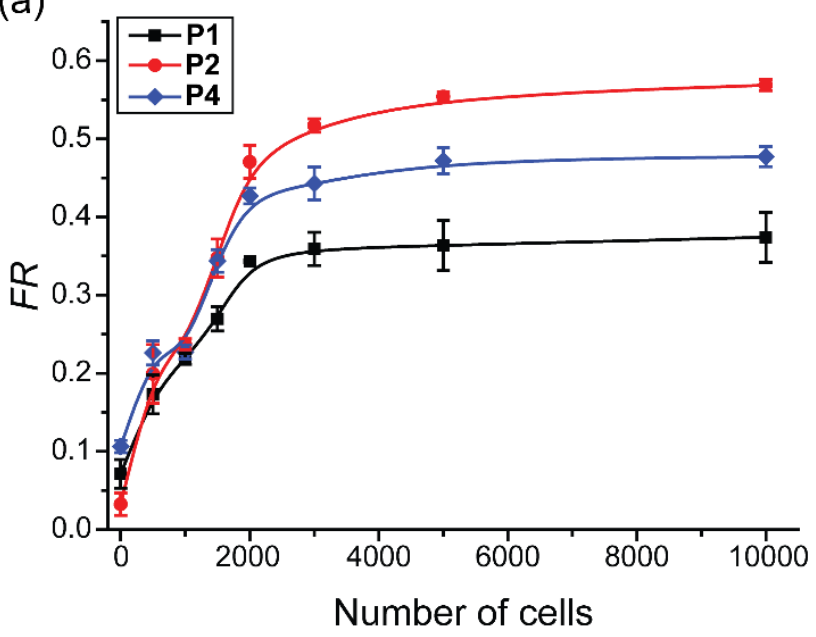

(b)

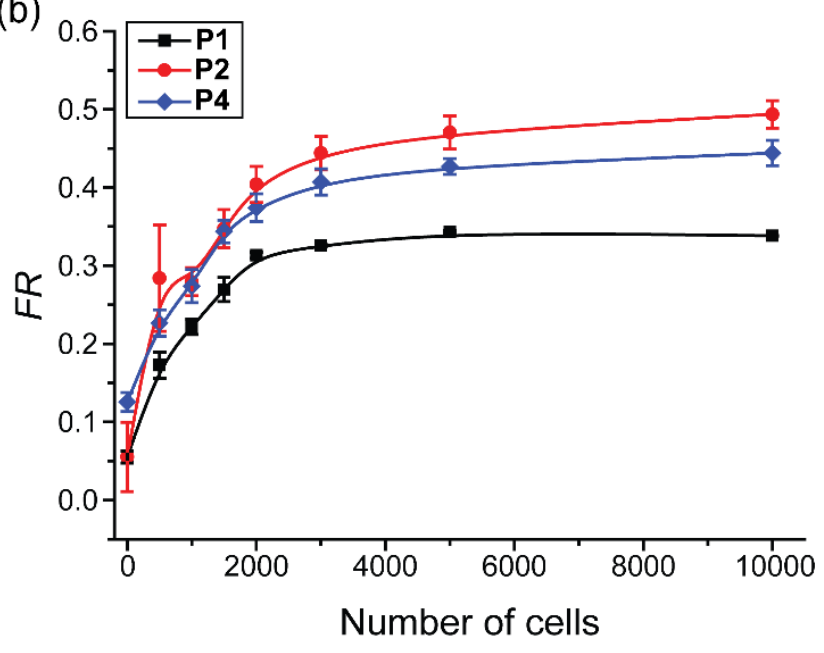

Figure S6. Change in the FRET response of the polymer P1, P2, and P4 upon incubation with different number of (a) CHO-K1 and (b) pgsA-745 cells. Each value is the average of three independent measurements and the error bars are the \pm SD. Solid lines are drawn to guide the eye.

A linear slope of FRET responses can be observed between 0 to 2000 cells, with a saturation at higher number of cells (Figure S6). The dose response behavior could be utilized for quantitatively detect cells within the observed dynamic range.

\section{S11. Aggregation behavior of polymer on cell surfaces}

Quenching of the polymers upon interaction with cell surfaces can be observed (see main text and reference 23 therein) that should arise from aggregation on cell surfaces. Confocal microscopy was employed to investigate the aggregation behavior of the polymers.

$2.4 \times 10^{5}$ cells (CHO-K1, MCF-7, and pTD) were seeded into round bottom culture discs in the respective culture media and grown for $24 \mathrm{~h}$ at $37^{\circ} \mathrm{C}$. Cells were washed and the media was replaced with 1 xPBS buffer. At this point, polymer solution was added $(0.7 \mu \mathrm{M}$ final concentration) to the cells and imaged after 15 min using Zeiss Meta 510 confocal laser scanning microscope.

The punctate patterns on the cell surfaces indicates aggregation of the polymer (Figure S7). The aggregation patterns appear to be dependent on cell type. 
(a) $\mathrm{CHO}-\mathrm{K} 1$

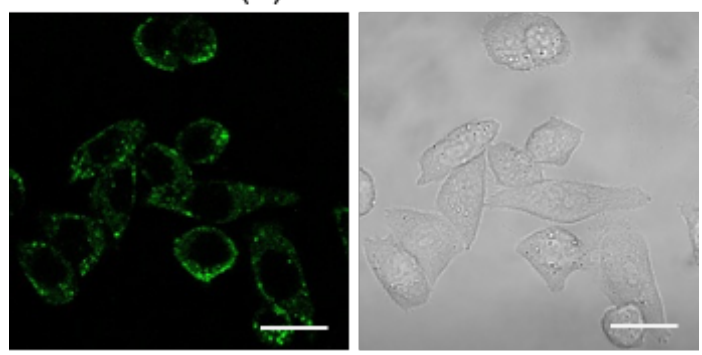

(b) MCF-7

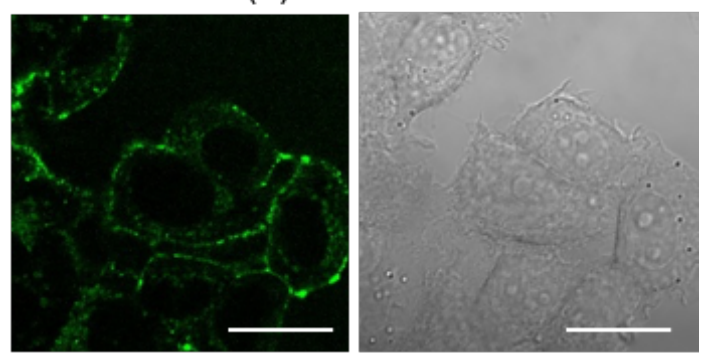

(c) pTD

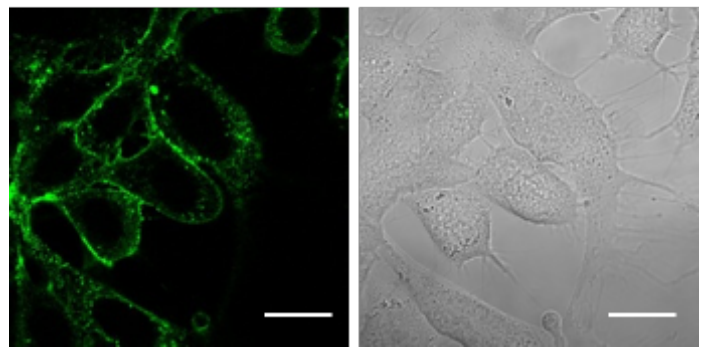

Figure S7. Confocal laser scanning micrograph (CLSM) showing the binding of P1 to cell surfaces. Representative images collected in the polymer fluorescence channel and bright field are respectively presented for (a) CHO-K1, (b) MCF-7, and (c) pTD cells. Scale bars: 20 microns.

\section{S12. Cell sensing}

In the sensing studies, GFP and CPs (P1-P4) were mixed at stoichiometric ratio in $5 \mathrm{mM}$ sodium phosphate buffer ( $\mathrm{pH}$ 7.4). Each of the CP-GFP complexes (same concentration ratio as that of polymer-GFP titration, section S6) in multiple replicates were loaded (200 $\mu \mathrm{L})$ into a black 96-well untreated plate (Costar) followed by incubation for $30 \mathrm{~min}$ at room temperature in dark. Fluorescence intensity was recorded on a Molecular Devices SpectraMax M5 microplate reader with excitation at $430 \mathrm{~nm}$ and cutoff at $455 \mathrm{~nm}$, providing the fluorescence "without cells". Then, cell suspensions (20 $\mu \mathrm{L}, \sim 2000$ cells) were added to each well of the plate containing the CP-GFP complexes, after which the fluorescence intensities were recorded at the same spectroscopic variables. The measured intensities provide the final fluorescence with cells. 


\section{S13. Statistical analysis}

Linear discriminant analysis (LDA) models the similarities between the data corresponding to the same cluster by introducing the group classification into the data set. The data are then used as a training set to generate a linear discriminant (LD) function (also called canonical functions or factors) that describes the best fit parameters to separate different clusters (analytes). The discriminants are linear combinations of the measured (independent) variables such as the sensor responses. Discriminant functions are calculated with the objective of maximizing the distance between classes relative to the variation within classes. The first discriminant is the linear combination of the variables that best discriminates among the groups; the second discriminant is orthogonal to the first and is the next best combination of variables, and so on. First discriminant function:

$$
L D=c+a_{1} x_{1}+a_{2} x_{2}+\ldots+a_{\mathrm{n}} x_{\mathrm{n}}
$$

where, $a_{1}$ through $a_{\mathrm{n}}$ are discriminant coefficients, $x_{1}$ through $x_{\mathrm{n}}$ are discriminating variables, and $c$ is a constant. In the discriminant score plot each response pattern generated can be reduced to a single score and plotted in the new discriminant space.

The jackknifed classification matrix presents the outcome of cross-validation (leave-one-out) routine in LDA. The analysis validates the correctness of sample classification by the sensor array by leaving out one sample observation of the set at a time, and uses the rest of the data as a training set to generate the discriminant function. The discriminant function is then used to reclassify the excluded observation within the correct cluster. This is performed for each observation, and the overall ability to classify the observations describes the quality and predictability of the array.

In the present analyses, classical LDA were performed using Systat (version 11.0) program. ${ }^{12}$ Herein, all variables were used in the model (complete mode) and the tolerance was set to 0.001 . The raw fluorescence responses were transformed to canonical scores setting the cell types as the grouping variable. These canonical scores were further plotted as scatterplot with $95 \%$ confidence ellipse. In the LD multidimensional space, the Mahalanobis distance is a measure of the distance of a data point to the centroid of a training group ${ }^{13}$ that can be calculated using discrim function in Systat. The identity of an unknown was predicted by deducing the Mahalanobis distance of the unknown data from the training groups. The unknowns were assigned to the cell type from which the distance was the shortest.

Hierarchical clustering analysis (HCA) on the data set was performed using the hclust function of the stats package of $\mathrm{R}$ assuming a complete linkage method. ${ }^{14}$ hclust begins with each case serving as its own cluster and the two most similar cases or clusters are joined at each step in the clustering process. This process iterates until all cases fall into a single cluster. 
(a)

\begin{tabular}{|c|c|c|c|c|}
\hline & $\mathrm{A}$ & $\mathrm{B}$ & $\mathrm{C}$ & $\%$ correct \\
\hline $\mathrm{A}$ & 8 & 0 & 0 & 100 \\
\hline $\mathrm{B}$ & 0 & 8 & 0 & 100 \\
\hline $\mathrm{C}$ & 0 & 0 & 8 & 100 \\
\hline Total & 8 & 8 & 8 & 100 \\
\hline
\end{tabular}
A : $\mathrm{CD} \beta \mathrm{Geo}$
B : pTD
C : V14

(c)

\begin{tabular}{|c|c|c|c|c|c|c|}
\hline & $\mathrm{H}$ & $\mathrm{I}$ & $\mathrm{J}$ & $\mathrm{K}$ & $\mathrm{L}$ & $\%$ correct \\
\hline $\mathrm{H}$ & 6 & 0 & 0 & 0 & 0 & 100 \\
\hline $\mathrm{I}$ & 0 & 6 & 0 & 0 & 0 & 100 \\
\hline $\mathrm{J}$ & 0 & 0 & 6 & 0 & 0 & 100 \\
\hline $\mathrm{K}$ & 0 & 0 & 0 & 6 & 0 & 100 \\
\hline $\mathrm{L}$ & 0 & 0 & 0 & 0 & 6 & 100 \\
\hline Total & 6 & 6 & 6 & 6 & 6 & 100 \\
\hline
\end{tabular}

$\mathrm{H}:$ HepG2 $\quad \mathrm{J}: \mathrm{NT2} \quad \mathrm{L}:$ HeLa

(b)

\begin{tabular}{|c|c|c|c|c|c|}
\hline & $D$ & $E$ & $F$ & $G$ & $\%$ correct \\
\hline$D$ & 8 & 0 & 0 & 0 & 100 \\
\hline$E$ & 0 & 8 & 0 & 0 & 100 \\
\hline$F$ & 0 & 0 & 8 & 0 & 100 \\
\hline$G$ & 0 & 0 & 0 & 8 & 100 \\
\hline Total & 8 & 8 & 8 & 8 & 100 \\
\hline
\end{tabular}

D : NCl-H1299

F : Subline-2

E : Subline-1

G : Subline-5

(d)

\begin{tabular}{|c|c|c|c|c|c|}
\hline & $\mathrm{M}$ & $\mathrm{N}$ & $\mathrm{O}$ & $\mathrm{P}$ & $\%$ correct \\
\hline $\mathrm{M}$ & 8 & 0 & 0 & 0 & 100 \\
\hline $\mathrm{N}$ & 0 & 8 & 0 & 0 & 100 \\
\hline $\mathrm{O}$ & 0 & 0 & 8 & 0 & 100 \\
\hline $\mathrm{P}$ & 0 & 0 & 0 & 8 & 100 \\
\hline Total & 8 & 8 & 8 & 8 & 100 \\
\hline
\end{tabular}

$\mathrm{M}: \mathrm{CHO}-\mathrm{K} 1$

O : pgsB-618

$\mathrm{N}$ : pgsA-745

P : pgsD-677

Figure S8: leave-one-out cross-validation analysis by Jackknifing in LDA for (a) murine mammary, (b) human NSCLC parental and site-specific metastatic, (c) human, and (d) CHO cell types. 


\section{S14. Fingerprinting of human cell types}

Table S5: Features of the human cell lines used in the study

\begin{tabular}{|c|c|c|c|}
\hline Cell line & $\begin{array}{l}\text { Tissue } \\
\text { origin }\end{array}$ & Features of the cell lines & Cell status \\
\hline MCF10A & Breast & Epithelial cells & Non-tumorigenic \\
\hline $\mathrm{HeLa}$ & Cervix & Epithelial cells & Tumorigenic \\
\hline HepG2 & Liver & Epithelial cells & Tumorigenic \\
\hline NT2/D1 & Testis & $\begin{array}{l}\text { Epithelial-like cells; derived from } \\
\text { metastatic site (lung) }\end{array}$ & Tumorigenic \\
\hline MCF7 & Breast & $\begin{array}{l}\text { Epithelial cell; derived from metastatic site } \\
\text { (pleural effusion) }\end{array}$ & Tumorigenic \\
\hline
\end{tabular}

(a)

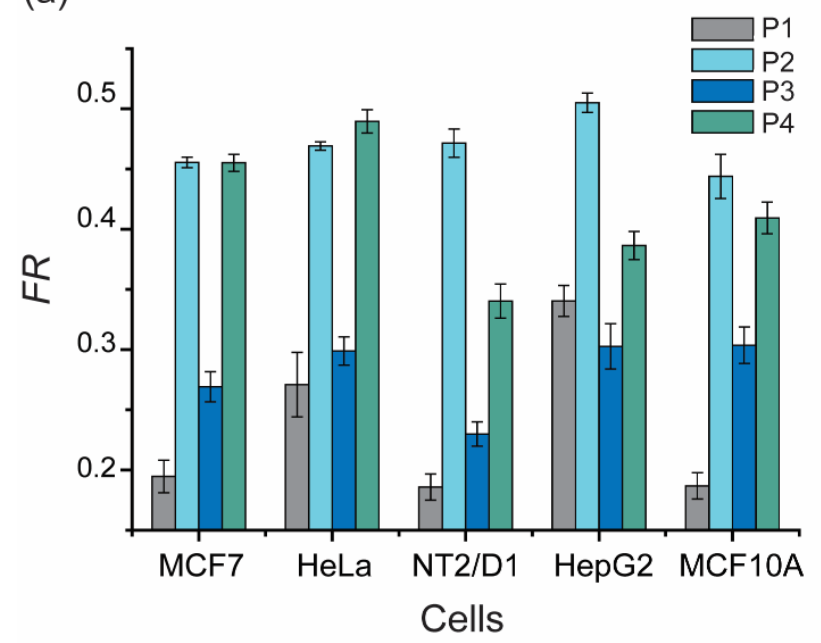

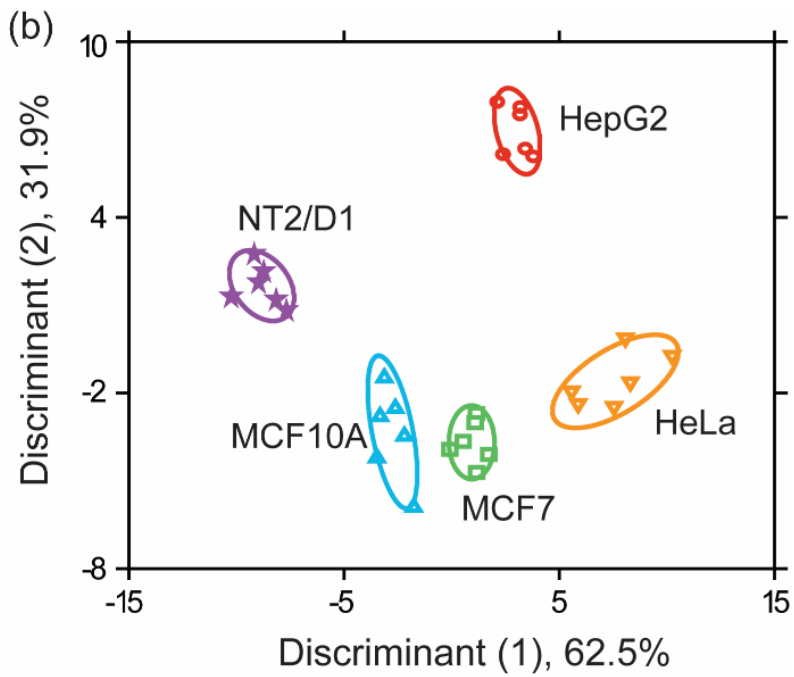

Figure S9. Detection of human cell types. (a) Change in FRET responses $(F R)$ from the polymer-GFP complexes upon interaction with the five human cell types, where each value is the average of six independent measurements and the error bars are the \pm SD. (b) LDA score plot of the fluorescence responses. The analysis resulted in canonical scores with three discriminants explaining $62.5 \%$, $31.9 \%$, and $5.6 \%$ of total variance and was plotted with $95 \%$ confidence ellipses around the centroid of each group. 


\section{S15. Glycomutant CHO cells: FRET responses}

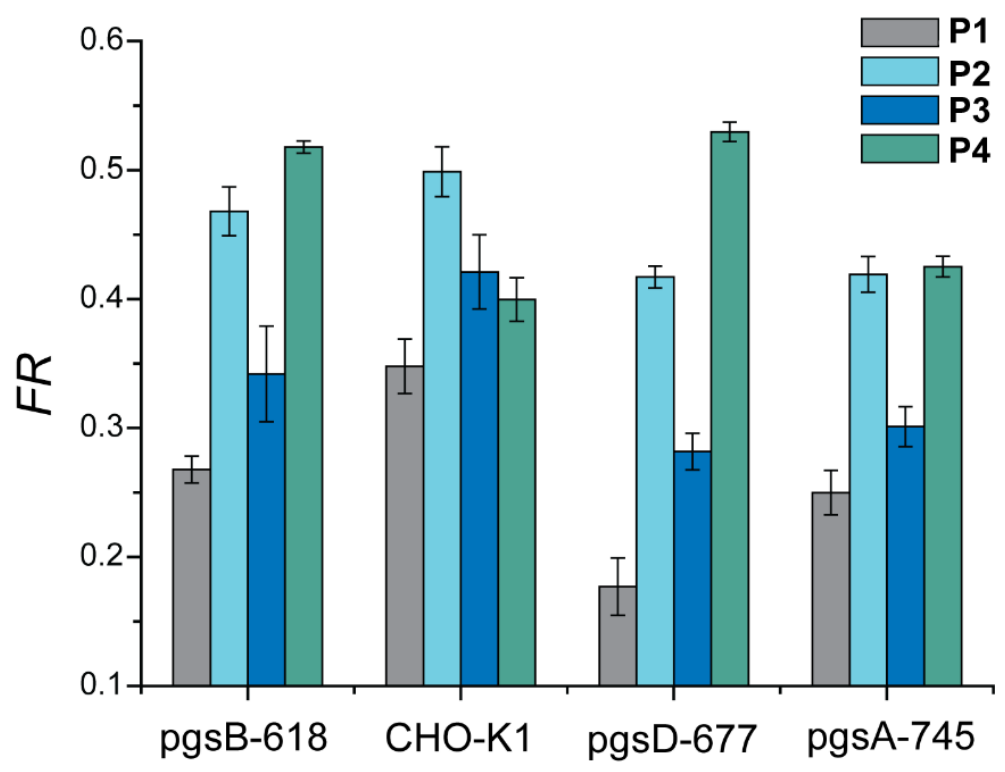

Figure S10: Change in FRET responses $(F R)$ from the sensor upon interacting with the CHO cell types, where each value is the average of eight independent measurements and the error bars are the $\pm \mathrm{SD}$.

\section{S16. Contribution of CPs towards the differential FRET responses}

Evaluating the contribution of each $\mathrm{CP}$ in the sensor output would validate their importance in generating the sensor array. Pearson's correlation was performed using Systat software.

It can be observed that depending on the cell types different CPs contribute to the discriminants to a different extent. However, all the polymers had significant correlation with the discriminants. 
(a) Murine isogenic mammary cell types

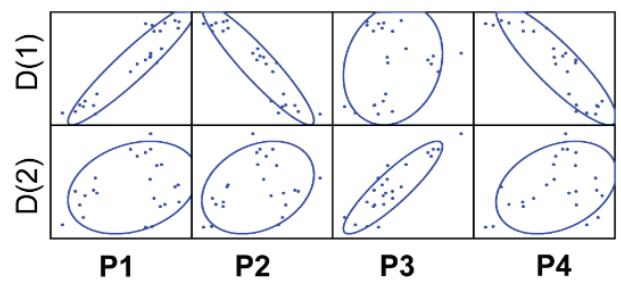

\begin{tabular}{|ccccc|}
\hline & P1 & P2 & P3 & P4 \\
\hline$D(1)$ & 0.941 & -0.927 & 0.182 & -0.882 \\
\hline$D(2)$ & 0.268 & 0.279 & 0.890 & 0.316 \\
\hline
\end{tabular}

(b) Human NSCLC site-specific metastatic cell types

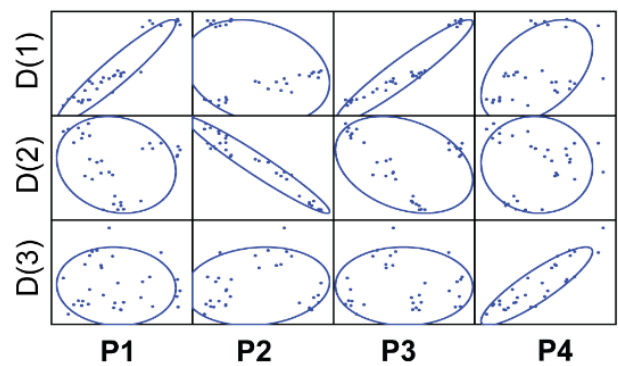

\begin{tabular}{|ccccc|}
\hline & P1 & P2 & P3 & P4 \\
\hline$D(1)$ & 0.944 & -0.220 & 0.946 & 0.466 \\
\hline$D(2)$ & -0.138 & -0.965 & -0.312 & -0.040 \\
\hline$D(3)$ & -0.046 & 0.117 & -0.017 & 0.881 \\
\hline
\end{tabular}

(c) Human cell types

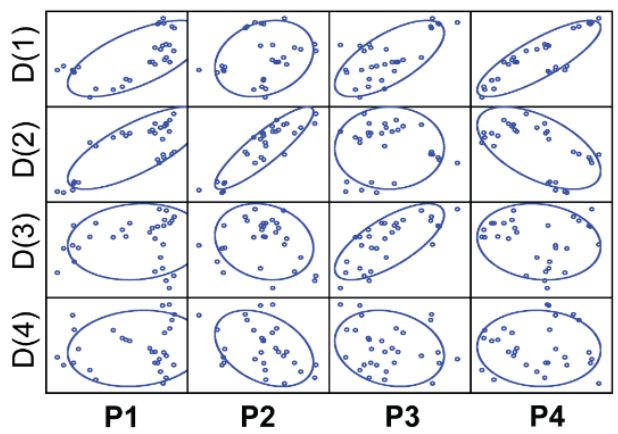

\begin{tabular}{|lcccc|}
\hline & P1 & P2 & P3 & P4 \\
\hline$D(1)$ & 0.652 & 0.234 & 0.679 & 0.820 \\
\hline$D(2)$ & 0.743 & 0.883 & 0.008 & -0.558 \\
\hline$D(3)$ & 0.099 & -0.170 & 0.707 & -0.197 \\
\hline$D(4)$ & 0.116 & -0.370 & -0.197 & -0.042 \\
\hline
\end{tabular}

(d) Glycomutant $\mathrm{CHO}$ cell types

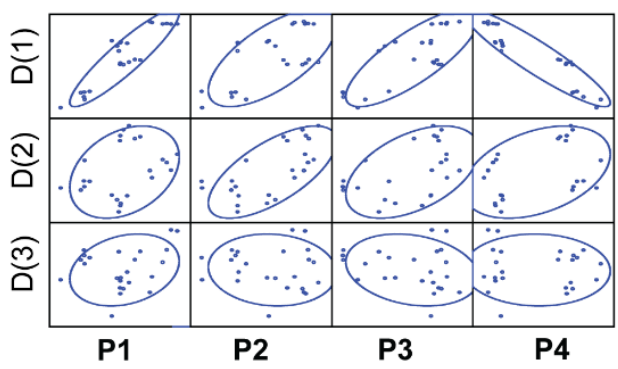

\begin{tabular}{|lcccc|}
\hline & P1 & P2 & P3 & P4 \\
\hline$D(1)$ & 0.825 & 0.565 & 0.668 & -0.915 \\
\hline$D(2)$ & 0.408 & 0.733 & 0.583 & 0.400 \\
\hline$D(3)$ & 0.390 & -0.251 & -0.365 & 0.015 \\
\hline
\end{tabular}

Figure S11. Pearson's correlation coefficients between the FRET responses and the discriminant scores generated by LDA. Here, D refers to the discriminants. The coefficients highlighted in green are the contributions of the corresponding polymers towards one discriminant.

Next, we investigated whether or not different all CP-GFP complexes provide equivalent or better classification efficiency than the combination of the four CPs using LDA on the fluorescence responses from different FP pairs (Figure S10a). In addition, identification of unknowns using the best differentiating CP-GFP combinations (Figure S10b) to verify the importance of each of the 
polymers in sensor array.

(a) Jackknifed classification matrix

\begin{tabular}{|l|c|c|c|c|}
\hline & \multicolumn{4}{|c|}{ \% Correct classification } \\
\hline P1 P2 P3 P4 & $\begin{array}{c}\text { Murine } \\
\text { mammary }\end{array}$ & $\begin{array}{c}\text { Site-specific } \\
\text { metastatic }\end{array}$ & Human & $\begin{array}{c}\text { Glycomutant } \\
\text { CHO }\end{array}$ \\
\hline & 79 & 84 & 57 & 83 \\
\hline & 92 & 72 & 77 & 46 \\
\hline & 58 & 100 & 60 & 67 \\
\hline & 75 & 50 & 93 & 75 \\
\hline & 100 & 100 & 100 & 100 \\
\hline & 92 & 100 & 97 & 100 \\
\hline & 88 & 100 & 87 & 96 \\
\hline & 100 & 100 & 87 & 100 \\
\hline & 88 & 100 & 90 & 92 \\
\hline & 96 & 100 & 90 & 79 \\
\hline & 100 & 100 & 100 & 100 \\
\hline & 100 & 100 & 100 & 100 \\
\hline & 100 & 100 & 100 & 100 \\
\hline
\end{tabular}

(b) Identification of unknown samples

\begin{tabular}{|llll|c|c|c|c|}
\hline \multicolumn{4}{|c|}{ Polymers } & \multicolumn{4}{|c|}{ \% Correct identification of cell types* } \\
\hline P1 & P2 & P3 & P4 & $\begin{array}{c}\text { Murine } \\
\text { mammary }\end{array}$ & $\begin{array}{c}\text { Site-specific } \\
\text { metastatic }\end{array}$ & Human & $\begin{array}{c}\text { Glycomutant } \\
\text { CHO }\end{array}$ \\
\hline & & $79.1(19 / 24)$ & $65.6(21 / 32)$ & $76.6(23 / 30)$ & $53.1(17 / 32)$ \\
\hline & & $91.6(22 / 24)$ & $84.3(27 / 32)$ & $86.6(26 / 30)$ & $84.3(27 / 32)$ \\
\hline & $83.3(20 / 24)$ & $78.1(25 / 32)$ & $73.3(22 / 30)$ & $65.6(21 / 32)$ \\
\hline & & $95.8(23 / 24)$ & $100(32 / 32)$ & $90.0(27 / 30)$ & $90.6(29 / 32)$ \\
\hline
\end{tabular}

* in the parentheses: correctly identified/total number of samples

Figure S12. (a) Jackknifed classification matrix obtained through LDA on the FRET responses for all the cell types. Different CP-GFP combinations were used to pick out the combinations with the best differentiation. (b) Identification of the unknowns using the CP-GFP combinations that provided the maximum separation across the cell types.

It is readily observed that the four CPs together provide the maximum efficiency of unknown identification. Overall, importance of each CP in the current biosensor array can be envisaged in classifying different types of cells and identifying the blinded unknowns. 


\section{S17. Glyco-mutant cell sensing using polymer only}

(a)

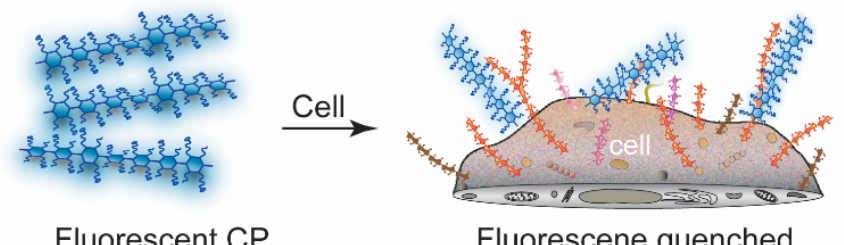

Fluorescent CP

Fluorescene quenched

(b)

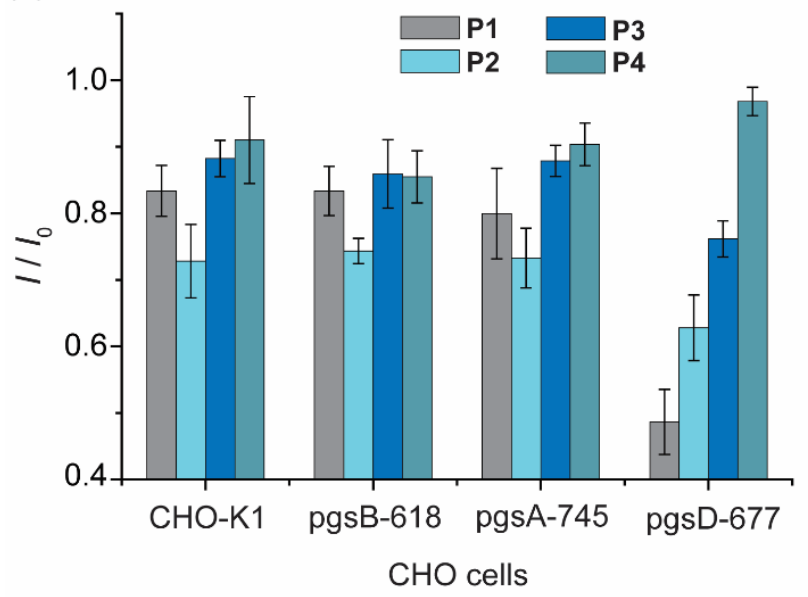

(c)

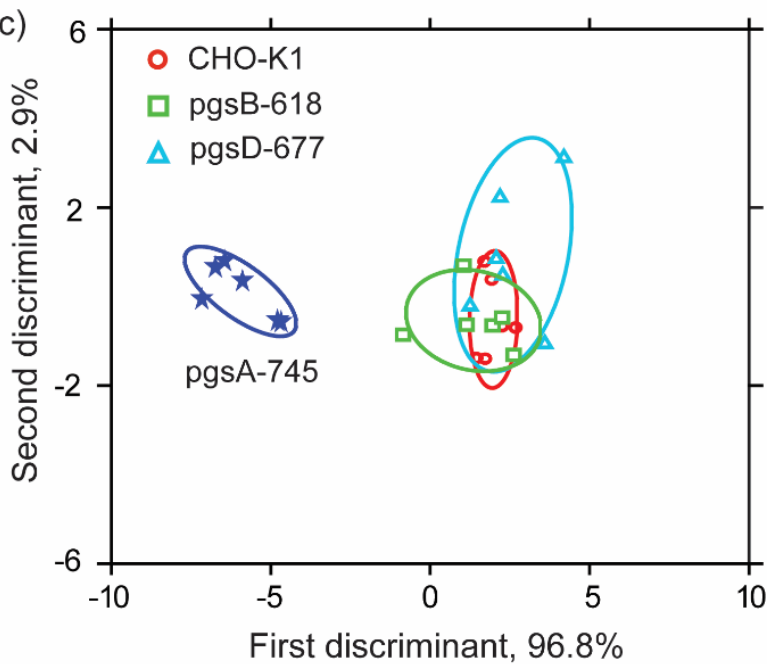

Figure S13. Detection of glyco-engineered cells using CPs only. (a) Schematic representation of the interaction of the polymers alone with cells, resulting in fluorescence quenching. (b) Change in fluorescence intensity of the polymers upon interaction with the parental and GAG-mutated cells, where $I$ and $I_{0}$ are respectively the fluorescence with and without the cells. The data are average of six independent replicates and the error bars represent the $\pm S D$. The experiment was performed simultaneously with the FRET system using the same set of cells. (c) LDA score plot of the fluorescence changes. The analysis resulted in canonical scores with three discriminants explaining $96.8 \%, 2.9 \%$, and $0.3 \%$ of total variance and was plotted with $95 \%$ confidence ellipses around the centroid of each group. 
S18. FRET response data for the training and test sets

Table S6. FRET responses and the LDA output obtained from the murine isogenic healthy, cancerous, and metastatic mammary cell types.

\begin{tabular}{|c|c|c|c|c|c|c|}
\hline \multirow{2}{*}{ Cells } & \multicolumn{4}{|c|}{$F R$} & \multicolumn{2}{|c|}{ LDA output } \\
\hline & P1 & P2 & P3 & P4 & Score(1) & Score(2) \\
\hline $\mathrm{CD} \beta \mathrm{Geo}$ & 0.2280 & 0.4871 & 0.3222 & 0.4729 & -6.8439 & 1.0188 \\
\hline $\mathrm{CD} \beta \mathrm{Geo}$ & 0.2295 & 0.4808 & 0.3043 & 0.4539 & -5.8071 & -0.1338 \\
\hline $\mathrm{CD} \beta \mathrm{Geo}$ & 0.2350 & 0.4823 & 0.2817 & 0.4899 & -7.0516 & 0.0101 \\
\hline $\mathrm{CD} \beta \mathrm{Geo}$ & 0.2608 & 0.4874 & 0.3146 & 0.4724 & -5.3393 & 1.3152 \\
\hline $\mathrm{CD} \beta \mathrm{Geo}$ & 0.2525 & 0.4969 & 0.3023 & 0.4836 & -6.6424 & 1.1708 \\
\hline $\mathrm{CD} \beta \mathrm{Geo}$ & 0.2749 & 0.5025 & 0.3221 & 0.4962 & -6.2921 & 2.6488 \\
\hline $\mathrm{CD} \beta \mathrm{Geo}$ & 0.2715 & 0.5015 & 0.2918 & 0.4641 & -5.2851 & 0.7725 \\
\hline $\mathrm{CD} \beta \mathrm{Geo}$ & 0.2862 & 0.5132 & 0.3086 & 0.5022 & -6.5517 & 2.7008 \\
\hline pTD & 0.3010 & 0.4306 & 0.2462 & 0.4467 & 0.0264 & -2.0372 \\
\hline pTD & 0.3127 & 0.4219 & 0.2379 & 0.4374 & 1.3137 & -2.4998 \\
\hline pTD & 0.2776 & 0.4482 & 0.2109 & 0.4388 & -1.7172 & -3.5408 \\
\hline pTD & 0.2669 & 0.4170 & 0.2976 & 0.4311 & -0.1469 & -1.4235 \\
\hline pTD & 0.2865 & 0.4430 & 0.2502 & 0.4307 & -0.6289 & -2.2820 \\
\hline pTD & 0.2784 & 0.4340 & 0.2982 & 0.4479 & -1.0650 & -0.5018 \\
\hline pTD & 0.2585 & 0.4418 & 0.2760 & 0.4484 & -2.4562 & -1.4787 \\
\hline pTD & 0.2775 & 0.4387 & 0.2438 & 0.4412 & -1.2550 & -2.5017 \\
\hline V14 & 0.3949 & 0.4092 & 0.3486 & 0.4131 & 7.0014 & 2.0527 \\
\hline V14 & 0.4313 & 0.4145 & 0.3359 & 0.4221 & 8.0535 & 2.5370 \\
\hline V14 & 0.4088 & 0.3883 & 0.2921 & 0.4306 & 7.8219 & 0.3049 \\
\hline V14 & 0.3740 & 0.3597 & 0.3090 & 0.4151 & 8.2299 & -0.5864 \\
\hline V14 & 0.3770 & 0.3927 & 0.3137 & 0.4142 & 6.8180 & 0.2261 \\
\hline V14 & 0.3712 & 0.4077 & 0.3000 & 0.4362 & 4.9511 & 0.4162 \\
\hline V14 & 0.4013 & 0.4048 & 0.3131 & 0.4303 & 6.7512 & 1.2159 \\
\hline V14 & 0.3919 & 0.4242 & 0.3030 & 0.4099 & 6.1154 & 0.5959 \\
\hline
\end{tabular}


Table S7. FRET responses and the LDA output obtained from the isogenic human NSCLC sitespecific metastatic cells.

\begin{tabular}{|c|c|c|c|c|c|c|c|}
\hline \multirow{2}{*}{ Cells } & \multicolumn{4}{|c|}{$F R$} & \multicolumn{3}{|c|}{ LDA output } \\
\hline & P1 & $\mathbf{P} 2$ & P3 & P4 & Score(1) & Score(2) & Score(3) \\
\hline $\mathrm{NCl}-\mathrm{H} 1299$ & 0.3545 & 0.5652 & 0.2824 & 0.4207 & -13.1734 & -2.5509 & -0.2951 \\
\hline $\mathrm{NCl}-\mathrm{H} 1299$ & 0.3349 & 0.5899 & 0.2667 & 0.4095 & -15.0856 & -3.4408 & -0.6537 \\
\hline $\mathrm{NCl}-\mathrm{H} 1299$ & 0.2580 & 0.5187 & 0.2705 & 0.4193 & -15.4893 & -1.4924 & -0.4532 \\
\hline $\mathrm{NCl}-\mathrm{H} 1299$ & 0.2569 & 0.5709 & 0.2874 & 0.4663 & -15.0392 & -2.9226 & 1.6351 \\
\hline $\mathrm{NCl}-\mathrm{H} 1299$ & 0.2599 & 0.5211 & 0.2753 & 0.4485 & -14.8575 & -1.2480 & 0.8364 \\
\hline $\mathrm{NCl}-\mathrm{H} 1299$ & 0.3271 & 0.5804 & 0.2724 & 0.4606 & -14.1513 & -2.5723 & 1.5914 \\
\hline $\mathrm{NCl}-\mathrm{H} 1299$ & 0.2514 & 0.5347 & 0.3072 & 0.4444 & -13.8187 & -2.3358 & 0.4072 \\
\hline $\mathrm{NCl}-\mathrm{H} 1299$ & 0.3038 & 0.5521 & 0.3086 & 0.3781 & -13.5554 & -3.4665 & -2.5171 \\
\hline Subline-1 & 0.5451 & 0.5347 & 0.5726 & 0.5075 & 8.0322 & -3.5765 & 1.4629 \\
\hline Subline-1 & 0.5737 & 0.5565 & 0.6250 & 0.4704 & 10.4856 & -5.4464 & -0.5686 \\
\hline Subline-1 & 0.5012 & 0.5326 & 0.6152 & 0.4906 & 8.7718 & -4.7323 & 0.3010 \\
\hline Subline-1 & 0.5232 & 0.5355 & 0.6142 & 0.5168 & 9.6131 & -4.3021 & 1.5283 \\
\hline Subline-1 & 0.5322 & 0.5812 & 0.6210 & 0.5078 & 9.2093 & -6.0270 & 1.1550 \\
\hline Subline-1 & 0.5601 & 0.5990 & 0.5962 & 0.5246 & 8.6196 & -5.8109 & 2.1852 \\
\hline Subline-1 & 0.5201 & 0.5556 & 0.6108 & 0.5077 & 8.8597 & -5.0797 & 1.1732 \\
\hline Subline-1 & 0.5045 & 0.5943 & 0.6307 & 0.5153 & 8.8009 & -6.7317 & 1.4127 \\
\hline Subline-2 & 0.4938 & 0.3521 & 0.4740 & 0.4092 & 3.8978 & 2.5414 & -2.5862 \\
\hline Subline-2 & 0.5008 & 0.4462 & 0.4901 & 0.4149 & 3.1912 & -0.8046 & -2.2795 \\
\hline Subline-2 & 0.5142 & 0.3689 & 0.5045 & 0.4350 & 5.9788 & 1.9774 & -1.6093 \\
\hline Subline-2 & 0.4375 & 0.3369 & 0.5453 & 0.4317 & 6.5047 & 1.8176 & -2.2345 \\
\hline Subline-2 & 0.4472 & 0.3592 & 0.4813 & 0.3717 & 2.3747 & 1.3383 & -4.3867 \\
\hline Subline-2 & 0.4694 & 0.3828 & 0.4830 & 0.4335 & 3.4364 & 1.4966 & -1.5305 \\
\hline Subline-2 & 0.4809 & 0.4075 & 0.5327 & 0.4159 & 5.5018 & -0.2932 & -2.6721 \\
\hline Subline-2 & 0.4683 & 0.4349 & 0.5037 & 0.4391 & 3.5283 & -0.5476 & -1.3488 \\
\hline Subline-5 & 0.4232 & 0.2487 & 0.3828 & 0.4517 & 0.0042 & 7.5890 & -0.1920 \\
\hline Subline-5 & 0.4346 & 0.2834 & 0.4100 & 0.4963 & 1.5983 & 6.6577 & 1.6908 \\
\hline Subline-5 & 0.4144 & 0.2762 & 0.4011 & 0.4996 & 0.7982 & 6.9392 & 1.8738 \\
\hline Subline-5 & 0.4150 & 0.2839 & 0.4208 & 0.5017 & 1.6699 & 6.3960 & 1.8274 \\
\hline
\end{tabular}




\begin{tabular}{|l|l|l|l|l|l|l|l|} 
Subline-5 & 0.4072 & 0.2554 & 0.3946 & 0.4862 & 0.4932 & 7.5216 & 1.2745 \\
Subline-5 & 0.4312 & 0.3137 & 0.4197 & 0.4889 & 1.3171 & 5.3385 & 1.3256 \\
Subline-5 & 0.4635 & 0.2568 & 0.4003 & 0.4737 & 2.0929 & 7.6252 & 0.7268 \\
Subline-5 & 0.3594 & 0.2707 & 0.4248 & 0.4844 & 0.3911 & 6.1429 & 0.9202 \\
\hline
\end{tabular}

Table S8. FRET responses and the LDA output obtained from human normal, cancerous, and metastatic cells.

\begin{tabular}{|c|c|c|c|c|c|c|c|c|}
\hline \multirow{2}{*}{ Cell } & \multicolumn{4}{|c|}{$F R$} & \multicolumn{4}{|c|}{ LDA output } \\
\hline & P1 & $\mathbf{P 2}$ & P3 & P4 & Score(1) & Score(2) & Score(3) & Score(4) \\
\hline HeLa & 0.3081 & 0.4668 & 0.3089 & 0.5004 & 10.245 & -0.783 & -0.354 & 0.956 \\
\hline HeLa & 0.2985 & 0.4663 & 0.2840 & 0.4822 & 8.073 & -0.186 & -1.545 & 1.372 \\
\hline HeLa & 0.2554 & 0.4695 & 0.3005 & 0.4975 & 7.546 & -2.522 & -0.977 & -0.407 \\
\hline HeLa & 0.2434 & 0.4683 & 0.2867 & 0.4855 & 5.877 & -2.429 & -1.545 & -0.282 \\
\hline HeLa & 0.2497 & 0.4682 & 0.2994 & 0.4761 & 5.572 & -1.994 & -0.385 & -0.323 \\
\hline HeLa & 0.2702 & 0.4760 & 0.3134 & 0.4958 & 8.304 & -1.684 & -0.314 & -0.738 \\
\hline HepG2 & 0.3509 & 0.5021 & 0.2921 & 0.3710 & 2.154 & 7.915 & 0.659 & 0.748 \\
\hline HepG2 & 0.3267 & 0.4999 & 0.2971 & 0.3880 & 2.422 & 6.130 & 0.616 & 0.060 \\
\hline HepG2 & 0.3611 & 0.5010 & 0.3232 & 0.3742 & 3.221 & 7.744 & 2.786 & 0.409 \\
\hline HepG2 & 0.3336 & 0.5059 & 0.3220 & 0.3973 & 3.823 & 6.057 & 1.823 & -0.759 \\
\hline HepG2 & 0.3346 & 0.5005 & 0.2742 & 0.3998 & 3.452 & 6.325 & -1.347 & 0.646 \\
\hline HepG2 & 0.3360 & 0.5210 & 0.3072 & 0.3883 & 3.208 & 7.488 & 0.397 & -1.374 \\
\hline MCF7 & 0.2108 & 0.4580 & 0.2762 & 0.4473 & 1.149 & -2.698 & -0.740 & 0.027 \\
\hline MCF7 & 0.2019 & 0.4491 & 0.2836 & 0.4598 & 1.728 & -4.094 & -0.199 & 0.179 \\
\hline MCF7 & 0.1782 & 0.4574 & 0.2723 & 0.4668 & 1.158 & -4.714 & -1.546 & -0.812 \\
\hline MCF7 & 0.1865 & 0.4610 & 0.2654 & 0.4547 & 0.534 & -3.647 & -1.838 & -0.626 \\
\hline MCF7 & 0.1838 & 0.4517 & 0.2468 & 0.4524 & -0.084 & -3.922 & -2.660 & 0.350 \\
\hline MCF7 & 0.2067 & 0.4557 & 0.2704 & 0.4501 & 1.093 & -3.011 & -1.127 & 0.186 \\
\hline NT2 & 0.1978 & 0.4679 & 0.2288 & 0.3352 & -8.735 & 2.159 & -1.254 & 0.660 \\
\hline NT2 & 0.1888 & 0.4510 & 0.2356 & 0.3224 & -10.249 & 1.296 & 0.315 & 1.525 \\
\hline NT2 & 0.1951 & 0.4751 & 0.2105 & 0.3331 & -9.173 & 2.756 & -2.780 & 0.494 \\
\hline NT2 & 0.1879 & 0.4701 & 0.2301 & 0.3375 & -8.972 & 1.782 & -1.328 & 0.209 \\
\hline
\end{tabular}




\begin{tabular}{|l|l|l|l|l|l|l|l|l|} 
NT2 & 0.1708 & 0.4832 & 0.2366 & 0.3611 & -7.682 & 0.829 & -2.113 & -1.410 \\
NT2 & 0.1746 & 0.4816 & 0.2373 & 0.3529 & -8.156 & 1.195 & -1.767 & -1.170 \\
\hline MCF10A & 0.2023 & 0.4428 & 0.2979 & 0.4031 & -2.619 & -2.457 & 2.696 & 0.650 \\
MCF10A & 0.1934 & 0.4376 & 0.2824 & 0.4166 & -2.194 & -3.406 & 1.456 & 1.028 \\
MCF10A & 0.1842 & 0.4262 & 0.2995 & 0.4046 & -3.476 & -4.145 & 3.484 & 1.283 \\
MCF10A & 0.1789 & 0.4606 & 0.3286 & 0.4008 & -3.326 & -2.739 & 4.128 & -1.827 \\
MCF10A & 0.1716 & 0.4254 & 0.3046 & 0.4330 & -1.762 & -5.831 & 3.060 & 0.739 \\
MCF10A & 0.1902 & 0.4706 & 0.3090 & 0.3984 & -3.128 & -1.414 & 2.399 & -1.791 \\
\hline
\end{tabular}

Table S9. FRET responses and the LDA output obtained from the glyco-mutant Chinese hamster ovary cells.

\begin{tabular}{|c|c|c|c|c|c|c|c|}
\hline \multirow{2}{*}{ Cells } & \multicolumn{4}{|c|}{$F R$} & \multicolumn{3}{|c|}{ LDA output } \\
\hline & P1 & $\mathbf{P 2}$ & P3 & P4 & Score(1) & Score(2) & Score(3) \\
\hline $\mathrm{CHO}-\mathrm{K} 1$ & 0.2839 & 0.4893 & 0.4860 & 0.4462 & 5.9525 & 1.7935 & -2.4950 \\
\hline CHO-K1 & 0.3475 & 0.4919 & 0.4424 & 0.4311 & 7.8344 & 1.9170 & -0.2380 \\
\hline $\mathrm{CHO}-\mathrm{K} 1$ & 0.3411 & 0.4913 & 0.3814 & 0.4143 & 7.8769 & 0.3988 & 0.1969 \\
\hline $\mathrm{CHO}-\mathrm{K} 1$ & 0.3404 & 0.4688 & 0.4432 & 0.4366 & 6.9720 & 1.4109 & 0.0901 \\
\hline $\mathrm{CHO}-\mathrm{K} 1$ & 0.3397 & 0.4582 & 0.4079 & 0.4201 & 7.4623 & 0.0285 & 0.5594 \\
\hline $\mathrm{CHO}-\mathrm{K} 1$ & 0.2954 & 0.4951 & 0.3707 & 0.4311 & 5.3767 & 0.2470 & -0.8958 \\
\hline $\mathrm{CHO}-\mathrm{K} 1$ & 0.2854 & 0.5228 & 0.4716 & 0.4259 & 7.7137 & 1.6985 & -3.2126 \\
\hline $\mathrm{CHO}-\mathrm{K} 1$ & 0.3893 & 0.5224 & 0.4196 & 0.4467 & 7.5623 & 3.9074 & 0.8909 \\
\hline pgsA-745 & 0.2504 & 0.4320 & 0.3312 & 0.4359 & 2.4674 & -2.5007 & -0.3331 \\
\hline pgsA-745 & 0.2620 & 0.4009 & 0.3010 & 0.4179 & 3.1946 & -4.2095 & 0.8453 \\
\hline pgsA-745 & 0.2479 & 0.4176 & 0.2880 & 0.4154 & 3.0355 & -4.2738 & 0.2178 \\
\hline pgsA-745 & 0.2594 & 0.4141 & 0.2992 & 0.4109 & 3.8075 & -4.2208 & 0.4267 \\
\hline pgsA-745 & 0.2658 & 0.4374 & 0.2949 & 0.4446 & 1.5626 & -2.1072 & 0.6216 \\
\hline pgsA-745 & 0.2777 & 0.3989 & 0.2922 & 0.4328 & 2.2216 & -3.4418 & 1.6688 \\
\hline pgsA-745 & 0.2595 & 0.4102 & 0.3327 & 0.4545 & 0.9953 & -2.1126 & 0.6125 \\
\hline pgsA-745 & 0.2664 & 0.4340 & 0.3384 & 0.4251 & 3.8268 & -2.5280 & -0.1298 \\
\hline pgsB-618 & 0.3015 & 0.4375 & 0.3048 & 0.5130 & -2.7206 & 1.5496 & 2.4313 \\
\hline pgsB-618 & 0.2834 & 0.4522 & 0.3045 & 0.5099 & -2.7214 & 1.4734 & 1.5451 \\
\hline
\end{tabular}




\begin{tabular}{|l|l|l|l|l|l|l|l|} 
pgsB-618 & 0.2649 & 0.4408 & 0.3770 & 0.5230 & -2.9949 & 2.1832 & 0.4087 \\
pgsB-618 & 0.2458 & 0.4527 & 0.3620 & 0.5159 & -3.0098 & 1.6824 & -0.3005 \\
pgsB-618 & 0.2725 & 0.4545 & 0.3866 & 0.5094 & -1.4241 & 2.2213 & 0.0470 \\
pgsB-618 & 0.2691 & 0.4854 & 0.3371 & 0.5237 & -3.1168 & 3.0377 & 0.1555 \\
pgsB-618 & 0.2999 & 0.4458 & 0.3363 & 0.5235 & -2.8974 & 2.5331 & 1.9159 \\
pgsB-618 & 0.3117 & 0.4855 & 0.3606 & 0.5136 & -0.9265 & 3.6607 & 0.9852 \\
\hline pgsD-677 & 0.2007 & 0.4351 & 0.3200 & 0.5396 & -6.8610 & 0.9157 & -0.4149 \\
pgsD-677 & 0.1539 & 0.4258 & 0.2792 & 0.5339 & -8.3536 & -0.8882 & -1.1455 \\
pgsD-677 & 0.1608 & 0.4281 & 0.3213 & 0.5126 & -5.7591 & -1.1321 & -1.8305 \\
pgsD-677 & 0.1782 & 0.4058 & 0.2805 & 0.5221 & -7.1056 & -1.4563 & -0.1662 \\
pgsD-677 & 0.1479 & 0.4150 & 0.2800 & 0.5202 & -7.5532 & -1.8560 & -1.2862 \\
pgsD-677 & 0.1697 & 0.4118 & 0.2885 & 0.5527 & -9.4485 & -0.0737 & -0.2648 \\
pgsD-677 & 0.2047 & 0.4160 & 0.3035 & 0.5270 & -6.3302 & -0.2340 & 0.1673 \\
pgsD-677 & 0.1837 & 0.4298 & 0.3337 & 0.5340 & -6.6395 & 0.3760 & -1.0730 \\
\hline
\end{tabular}

Table S10. Identification of the blinded unknowns from the murine healthy, cancerous, and metastatic cells using the FRET sensor. LDA was performed on the fluorescence responses of the training set and the unknowns at the same time, and the Mahalanobis distance of each unknown from the centroid of training groups was calculated. The training set included all the five human cell types. Based on the shortest Mahalanobis distance (data that are green colored) from a training group, an unknown is assigned to that particular group. Wrong identifications are red colored. Distance from the groups: $d(1)=C D \beta G e o ; d(2)=V 14 ; d(3)=$ pTD cells.

\begin{tabular}{|c|c|c|c|c|c|c|c|c|c|}
\hline \multirow{2}{*}{$\begin{array}{l}\text { Unknown } \\
\text { sample \# }\end{array}$} & \multicolumn{4}{|c|}{$F R$} & \multicolumn{3}{|c|}{ (Mahalanobis distance) $^{2}$} & \multirow{2}{*}{$\begin{array}{c}\text { Predicted } \\
\text { as }\end{array}$} & \multirow{2}{*}{$\begin{array}{l}\text { Accuracy of } \\
\text { identification }\end{array}$} \\
\hline & P1 & $\mathbf{P 2}$ & P3 & P4 & $d(1)$ & $d(2)$ & $d(3)$ & & \\
\hline 1 & 0.3262 & 0.4354 & 0.2268 & 0.5441 & 88.65 & 170.51 & 83.50 & pTD & Yes \\
\hline 2 & 0.3214 & 0.5053 & 0.3811 & 0.4944 & 24.01 & 142.96 & 68.35 & $\mathrm{CD} \beta \mathrm{Geo}$ & Yes \\
\hline 3 & 0.2766 & 0.4900 & 0.3684 & 0.5037 & 13.98 & 177.71 & 68.94 & $\mathrm{CD} \beta \mathrm{Geo}$ & Yes \\
\hline 4 & 0.4458 & 0.4218 & 0.3699 & 0.4172 & 231.95 & 15.33 & 127.32 & V14 & Yes \\
\hline 5 & 0.2342 & 0.3891 & 0.3434 & 0.4921 & 64.56 & 139.08 & 59.31 & pTD & Yes \\
\hline 6 & 0.2714 & 0.5001 & 0.3171 & 0.5188 & 11.68 & 212.82 & 73.76 & $\mathrm{CD} \beta \mathrm{Geo}$ & Yes \\
\hline 7 & 0.2836 & 0.4920 & 0.3401 & 0.5043 & 8.95 & 168.92 & 57.26 & $\mathrm{CD} \beta \mathrm{Geo}$ & Yes \\
\hline
\end{tabular}




\begin{tabular}{|c|cccc|ccc|c|c|}
\hline 8 & 0.3637 & 0.3447 & 0.3148 & 0.4421 & 211.26 & 22.71 & 92.20 & V14 & Yes \\
\hline 9 & 0.3099 & 0.4414 & 0.3452 & 0.4768 & 35.93 & 70.73 & 26.50 & pTD & Yes \\
\hline 10 & 0.3963 & 0.3887 & 0.3916 & 0.4175 & 213.17 & 12.89 & 111.01 & V14 & Yes \\
\hline 11 & 0.3248 & 0.4387 & 0.2724 & 0.4405 & 57.05 & 37.92 & 5.58 & pTD & Yes \\
\hline 12 & 0.3333 & 0.3799 & 0.2903 & 0.4621 & 116.19 & 31.63 & 38.61 & V14 & No \\
\hline 13 & 0.3116 & 0.4001 & 0.2020 & 0.4950 & 96.64 & 102.73 & 42.14 & pTD & Yes \\
\hline 14 & 0.3110 & 0.4083 & 0.2164 & 0.5316 & 103.39 & 156.73 & 77.65 & pTD & Yes \\
\hline 15 & 0.3783 & 0.3201 & 0.3806 & 0.4474 & 289.31 & 53.01 & 164.19 & V14 & Yes \\
\hline 16 & 0.3333 & 0.5137 & 0.3079 & 0.5133 & 18.82 & 157.57 & 60.36 & CD $\beta G e o$ & Yes \\
\hline 17 & 0.3989 & 0.2136 & 0.3625 & 0.4146 & 630.37 & 199.52 & 405.87 & V14 & Yes \\
\hline 18 & 0.3642 & 0.2565 & 0.3552 & 0.4141 & 440.90 & 107.35 & 256.40 & V14 & Yes \\
\hline 19 & 0.3359 & 0.3290 & 0.3468 & 0.4142 & 232.68 & 27.55 & 105.02 & V14 & Yes \\
\hline 20 & 0.3008 & 0.4890 & 0.3811 & 0.4745 & 19.81 & 122.75 & 50.67 & CD $\beta G e o$ & Yes \\
\hline 21 & 0.3233 & 0.3930 & 0.2137 & 0.4606 & 106.77 & 53.96 & 25.95 & pTD & Yes \\
\hline 22 & 0.2642 & 0.5019 & 0.3285 & 0.4716 & 2.24 & 166.14 & 44.16 & CD $\beta G e o$ & Yes \\
\hline 23 & 0.2488 & 0.4920 & 0.3948 & 0.5046 & 21.74 & 221.00 & 94.60 & CD $\beta G e o$ & Yes \\
\hline 24 & 0.3581 & 0.2324 & 0.3900 & 0.4278 & 505.03 & 159.62 & 321.68 & V14 & Yes \\
\hline
\end{tabular}

Table S11. Identification of the blinded unknowns from the human isogenic site-specific NSCLC metastatic cell lines using the FRET sensor. LDA was performed on the fluorescence responses of the training set and the unknowns at the same time, and the Mahalanobis distance of each unknown from the centroid of training groups was calculated. The training set included all the four murine cell types. Based on the shortest Mahalanobis distance (data that are green colored) from a training group, an unknown is assigned to that particular group. Wrong identifications are red colored. Distance from the groups: $d(1)=\mathrm{NCl}-\mathrm{H} 1299 ; \mathrm{d}(2)=$ Subline- $1 ; \mathrm{d}(3)=$ Subline- 2 ; $d(4)=$ Subline-5.

\begin{tabular}{|c|cccc|cccc|c|c|}
\hline \multirow{2}{*}{$\begin{array}{c}\text { Unknown } \\
\text { sample \# }\end{array}$} & \multicolumn{4}{|c|}{$\boldsymbol{F R}$} & \multicolumn{4}{|c|}{ (Mahalanobis distance) $^{\mathbf{2}}$} & \multirow{2}{*}{$\begin{array}{c}\text { Predicted } \\
\text { as }\end{array}$} & $\begin{array}{c}\text { Accuracy of } \\
\text { identification }\end{array}$ \\
\cline { 2 - 11 } & $\mathbf{P 1}$ & $\mathbf{P 2}$ & $\mathbf{P 3}$ & $\mathbf{P 4}$ & $\mathbf{d ( 1 )}$ & $\mathbf{d}(\mathbf{2})$ & $\mathbf{d}(\mathbf{3})$ & $\mathbf{d}(\mathbf{4})$ & & Yes \\
\hline 1 & 0.5470 & 0.5294 & 0.5924 & 0.4604 & 0.5470 & 5.08 & 48.24 & 183.82 & Subline-1 & Yes \\
\hline 2 & 0.2380 & 0.5284 & 0.2688 & 0.4011 & 0.2380 & 670.89 & 446.72 & 397.09 & NCl-H1299 & Yes \\
\hline 3 & 0.5296 & 0.3641 & 0.5659 & 0.4806 & 0.5296 & 52.88 & 40.23 & 107.92 & Subline-2 & Yes \\
\hline 4 & 0.5231 & 0.5493 & 0.6102 & 0.4533 & 0.5231 & 6.44 & 59.49 & 211.21 & Subline-1 & \\
\hline
\end{tabular}




\begin{tabular}{|c|c|c|c|c|c|c|c|c|c|c|}
\hline 5 & 0.5272 & 0.5305 & 0.6099 & 0.4947 & 0.5272 & 1.18 & 61.20 & 192.00 & Subline-1 & Yes \\
\hline 6 & 0.4926 & 0.3544 & 0.5630 & 0.4980 & 0.4926 & 56.33 & 37.76 & 91.45 & Subline-2 & Yes \\
\hline 7 & 0.2322 & 0.5281 & 0.3328 & 0.4017 & 0.2322 & 527.95 & 341.96 & 327.75 & $\mathrm{NCl}-\mathrm{H} 1299$ & Yes \\
\hline 8 & 0.5291 & 0.5811 & 0.5951 & 0.4970 & 0.5291 & 2.24 & 67.08 & 202.15 & Subline-1 & Yes \\
\hline 9 & 0.2347 & 0.5311 & 0.3018 & 0.3612 & 0.2347 & 633.40 & 418.71 & 403.69 & $\mathrm{NCl}-\mathrm{H} 1299$ & Yes \\
\hline 10 & 0.5282 & 0.5685 & 0.5844 & 0.5024 & 0.5282 & 2.72 & 59.05 & 182.53 & Subline-1 & Yes \\
\hline 11 & 0.2825 & 0.5404 & 0.2924 & 0.3922 & 0.2825 & 570.14 & 368.70 & 342.64 & $\mathrm{NCl}-\mathrm{H} 1299$ & Yes \\
\hline 12 & 0.2586 & 0.5332 & 0.3316 & 0.3917 & 0.2586 & 507.85 & 324.34 & 316.84 & $\mathrm{NCl}-\mathrm{H} 1299$ & Yes \\
\hline 13 & 0.4120 & 0.2932 & 0.4637 & 0.5539 & 0.4120 & 159.62 & 66.00 & 19.12 & Subline-5 & Yes \\
\hline 14 & 0.4651 & 0.3305 & 0.4665 & 0.5255 & 0.4651 & 120.87 & 39.91 & 19.84 & Subline-5 & Yes \\
\hline 15 & 0.2941 & 0.5418 & 0.2459 & 0.4296 & 0.2941 & 644.37 & 427.02 & 361.50 & $\mathrm{NCl}-\mathrm{H} 1299$ & Yes \\
\hline 16 & 0.2395 & 0.5354 & 0.2636 & 0.4469 & 0.2395 & 654.59 & 441.69 & 373.32 & $\mathrm{NCl}-\mathrm{H} 1299$ & Yes \\
\hline 17 & 0.5324 & 0.4066 & 0.5408 & 0.4973 & 0.5324 & 40.77 & 28.60 & 87.04 & Subline-2 & Yes \\
\hline 18 & 0.3553 & 0.2410 & 0.4389 & 0.5326 & 0.3553 & 218.78 & 81.19 & 10.25 & Subline-5 & Yes \\
\hline 19 & 0.5394 & 0.5582 & 0.6217 & 0.4506 & 0.5394 & 7.13 & 71.58 & 234.51 & Subline-1 & Yes \\
\hline 20 & 0.4955 & 0.3591 & 0.5165 & 0.5160 & 0.4955 & 72.41 & 31.97 & 53.88 & Subline-2 & Yes \\
\hline 21 & 0.5161 & 0.3480 & 0.5264 & 0.5217 & 0.5161 & 77.85 & 45.75 & 69.80 & Subline-2 & Yes \\
\hline 22 & 0.2654 & 0.5558 & 0.2883 & 0.4204 & 0.2654 & 590.91 & 395.62 & 358.98 & $\mathrm{NCl}-\mathrm{H} 1299$ & Yes \\
\hline 23 & 0.5370 & 0.3896 & 0.5647 & 0.4835 & 0.5370 & 41.88 & 37.02 & 110.23 & Subline-2 & Yes \\
\hline 24 & 0.5137 & 0.3569 & 0.5523 & 0.4970 & 0.5137 & 59.07 & 37.96 & 88.37 & Subline-2 & Yes \\
\hline 25 & 0.4705 & 0.2761 & 0.4476 & 0.5233 & 0.4705 & 167.35 & 61.34 & 17.51 & Subline-5 & Yes \\
\hline 26 & 0.4453 & 0.2270 & 0.4115 & 0.5411 & 0.4453 & 245.16 & 105.03 & 18.88 & Subline-5 & Yes \\
\hline 27 & 0.5172 & 0.4005 & 0.5467 & 0.4968 & 0.5172 & 40.17 & 27.28 & 86.42 & Subline-2 & Yes \\
\hline 28 & 0.4401 & 0.2378 & 0.4524 & 0.5440 & 0.4401 & 199.98 & 87.49 & 25.75 & Subline-5 & Yes \\
\hline 29 & 0.4414 & 0.2583 & 0.4390 & 0.5424 & 0.4414 & 195.78 & 80.12 & 16.94 & Subline-5 & Yes \\
\hline 30 & 0.5394 & 0.5991 & 0.5839 & 0.4893 & 0.5394 & 6.12 & 68.39 & 205.71 & Subline-1 & Yes \\
\hline 31 & 0.5196 & 0.5715 & 0.5969 & 0.4823 & 0.5196 & 3.45 & 61.32 & 199.80 & Subline-1 & Yes \\
\hline 32 & 0.4325 & 0.2584 & 0.4580 & 0.5529 & 0.4325 & 184.62 & 81.88 & 24.65 & Subline-5 & Yes \\
\hline
\end{tabular}


Table S12. Identification of the blinded unknowns from the glyco-mutated cells using the FRET sensor. LDA was performed on the fluorescence responses of the training set and the unknowns at the same time, and the Mahalanobis distance of each unknown from the centroid of training groups was calculated. The training set included all the five human cell types. Based on the shortest Mahalanobis distance (data that are green colored) from a training group, an unknown is assigned to that particular group. Wrong identifications are red colored. Distance from the groups: $d(1)=$ CHO-K1; $d(2)=$ pgsA-745; $d(3)=$ pgsB-618; $d(4)=$ pgsD-677 cells.

\begin{tabular}{|c|c|c|c|c|c|c|c|c|c|c|}
\hline \multirow{2}{*}{$\begin{array}{l}\text { Unknown } \\
\text { sample \# }\end{array}$} & \multicolumn{4}{|c|}{$F R$} & \multicolumn{4}{|c|}{ (Mahalanobis distance) $^{2}$} & \multirow{2}{*}{$\begin{array}{l}\text { Predicted } \\
\text { as }\end{array}$} & \multirow{2}{*}{$\begin{array}{l}\text { Accuracy of } \\
\text { identification }\end{array}$} \\
\hline & P1 & P2 & P3 & P4 & $d(1)$ & $d(2)$ & $d(3)$ & $d(4)$ & & \\
\hline 1 & 0.3917 & 0.3690 & 0.3110 & 0.4585 & 76.78 & 45.67 & 74.06 & 156.75 & pgsA-745 & Yes \\
\hline 2 & 0.3626 & 0.4756 & 0.4298 & 0.4540 & 7.02 & 46.30 & 73.17 & 189.61 & $\mathrm{CHO}-\mathrm{K} 1$ & Yes \\
\hline 3 & 0.2855 & 0.4301 & 0.3195 & 0.5733 & 232.82 & 158.38 & 32.59 & 31.63 & pgsD-677 & No \\
\hline 4 & 0.2686 & 0.4441 & 0.3200 & 0.5462 & 169.56 & 104.68 & 10.88 & 18.06 & pgsB-618 & Yes \\
\hline 5 & 0.3668 & 0.4942 & 0.4176 & 0.4420 & 3.19 & 51.68 & 90.18 & 215.35 & $\mathrm{CHO}-\mathrm{K} 1$ & Yes \\
\hline 6 & 0.1903 & 0.4040 & 0.2988 & 0.4842 & 131.05 & 40.13 & 28.07 & 18.26 & pgsD-677 & Yes \\
\hline 7 & 0.2736 & 0.4270 & 0.3256 & 0.5583 & 199.08 & 126.49 & 20.47 & 21.88 & pgsB-618 & Yes \\
\hline 8 & 0.3703 & 0.4144 & 0.3006 & 0.4444 & 39.04 & 21.31 & 59.84 & 147.05 & pgsA-745 & Yes \\
\hline 9 & 0.2398 & 0.4198 & 0.2967 & 0.5245 & 160.71 & 77.48 & 12.56 & 8.10 & pgsD-677 & Yes \\
\hline 10 & 0.4382 & 0.3447 & 0.3140 & 0.4406 & 100.72 & 80.86 & 136.06 & 242.33 & pgsA-745 & Yes \\
\hline 11 & 0.2227 & 0.4200 & 0.2901 & 0.5180 & 161.08 & 72.88 & 15.49 & 5.54 & pgsD-677 & Yes \\
\hline 12 & 0.3396 & 0.3814 & 0.2652 & 0.4321 & 62.33 & 15.47 & 71.34 & 137.73 & pgsA-745 & Yes \\
\hline 13 & 0.2982 & 0.4305 & 0.3509 & 0.5734 & 214.02 & 152.83 & 29.33 & 39.78 & pgsB-618 & Yes \\
\hline 14 & 0.3333 & 0.5106 & 0.3443 & 0.3876 & 22.19 & 63.42 & 162.24 & 287.35 & $\mathrm{CHO}-\mathrm{K} 1$ & Yes \\
\hline 15 & 0.2985 & 0.4167 & 0.3171 & 0.5522 & 185.77 & 116.20 & 19.02 & 30.12 & pgsB-618 & Yes \\
\hline 16 & 0.3088 & 0.4270 & 0.3208 & 0.5350 & 140.23 & 84.72 & 8.01 & 34.07 & pgsB-618 & Yes \\
\hline 17 & 0.2721 & 0.4177 & 0.2703 & 0.5390 & 190.19 & 103.54 & 19.10 & 16.30 & pgsD-677 & Yes \\
\hline 18 & 0.3568 & 0.4025 & 0.2537 & 0.4402 & 57.24 & 18.18 & 60.12 & 132.19 & pgsA-745 & Yes \\
\hline 19 & 0.2064 & 0.4548 & 0.3389 & 0.5406 & 177.38 & 105.12 & 17.58 & 6.70 & pgsD-677 & No \\
\hline 20 & 0.2034 & 0.4347 & 0.3449 & 0.5449 & 192.49 & 111.50 & 21.97 & 4.93 & pgsD-677 & Yes \\
\hline 21 & 0.3401 & 0.5006 & 0.3441 & 0.4240 & 9.52 & 36.83 & 91.37 & 200.76 & $\mathrm{CHO}-\mathrm{K} 1$ & Yes \\
\hline 22 & 0.1964 & 0.4206 & 0.2975 & 0.4966 & 137.31 & 50.47 & 20.28 & 10.46 & pgsD-677 & Yes \\
\hline 23 & 0.2076 & 0.4634 & 0.3468 & 0.5475 & 185.24 & 116.84 & 20.03 & 9.74 & pgsD-677 & Yes \\
\hline
\end{tabular}




\begin{tabular}{|l|llll|llll|l|l|l|}
\hline 24 & 0.3158 & 0.4747 & 0.3610 & 0.4290 & 6.54 & 19.13 & 72.09 & 166.80 & CHO-K1 & Yes \\
\hline 25 & 0.3315 & 0.3557 & 0.3307 & 0.4622 & 84.98 & 34.54 & 61.03 & 117.52 & pgsA-745 & Yes \\
\hline 26 & 0.3141 & 0.4807 & 0.3953 & 0.4432 & 4.28 & 24.15 & 60.91 & 156.16 & CHO-K1 & Yes \\
\hline 27 & 0.3593 & 0.3661 & 0.3011 & 0.4623 & 81.52 & 35.10 & 58.02 & 122.71 & pgsA-745 & Yes \\
\hline 28 & 0.3237 & 0.4818 & 0.4029 & 0.4247 & 1.06 & 32.66 & 93.20 & 202.66 & CHO-K1 & Yes \\
\hline 29 & 0.3529 & 0.4887 & 0.3842 & 0.4226 & 3.00 & 41.60 & 102.76 & 223.42 & CHO-K1 & Yes \\
\hline 30 & 0.2143 & 0.4098 & 0.3216 & 0.4650 & 83.63 & 15.43 & 28.69 & 43.36 & pgsA-745 & No \\
\hline 31 & 0.3926 & 0.3576 & 0.3332 & 0.4123 & 69.93 & 56.17 & 146.12 & 252.18 & pgsA-745 & Yes \\
\hline 32 & 0.2854 & 0.4284 & 0.3202 & 0.5150 & 110.75 & 55.02 & 3.02 & 28.46 & pgsB-618 & Yes \\
\hline
\end{tabular}

Table S13. Identification of the blinded unknowns from the human cell lines using the FRET sensor. LDA was performed on the fluorescence responses of the training set and the unknowns at the same time, and the Mahalanobis distance of each unknown from the centroid of training groups was calculated. The training set included all the five human cell types. Based on the shortest Mahalanobis distance (data that are green colored) from a training group, an unknown is assigned to that particular group. Wrong identifications are red colored. Distance from the groups: $\mathrm{d}(1)=\mathrm{HeLa}$; $\mathrm{d}(2)=$ HepG2; $\mathrm{d}(3)=$ MCF7; $\mathrm{d}(4)=\mathrm{NT} 2 ; \mathrm{d}(5)=$ MCF10A.

\begin{tabular}{|c|c|c|c|c|c|c|c|c|c|c|c|}
\hline \multirow{2}{*}{$\begin{array}{l}\text { Unknown } \\
\text { sample \# }\end{array}$} & \multicolumn{4}{|c|}{$F R$} & \multicolumn{5}{|c|}{ (Mahalanobis distance) $^{2}$} & \multirow{2}{*}{$\begin{array}{c}\text { Predicted } \\
\text { as }\end{array}$} & \multirow{2}{*}{$\begin{array}{c}\text { Accuracy } \\
\text { of } \\
\text { identifica- } \\
\text { tion }\end{array}$} \\
\hline & P1 & P2 & P3 & P4 & $d(1)$ & $d(2)$ & $d(3)$ & $d(4)$ & $d(5)$ & & \\
\hline 1 & 0.2584 & 0.4859 & 0.3472 & 0.5512 & 40.80 & 223.05 & 146.18 & 504.81 & 253.25 & HeLa & Yes \\
\hline 2 & 0.2195 & 0.5085 & 0.2290 & 0.4085 & 122.52 & 80.43 & 61.11 & 70.73 & 102.20 & MCF7 & No \\
\hline 3 & 0.2668 & 0.4660 & 0.2734 & 0.5335 & 20.00 & 181.69 & 98.90 & 405.27 & 221.01 & HeLa & Yes \\
\hline 4 & 0.2010 & 0.3844 & 0.3173 & 0.4278 & 164.24 & 249.51 & 83.90 & 202.48 & 40.62 & MCF10A & Yes \\
\hline 5 & 0.2218 & 0.4384 & 0.2913 & 0.4402 & 51.90 & 109.88 & 9.84 & 131.99 & 18.79 & MCF7 & Yes \\
\hline 6 & 0.1705 & 0.4296 & 0.2782 & 0.4302 & 115.65 & 177.22 & 20.03 & 97.53 & 7.75 & MCF10A & Yes \\
\hline 7 & 0.3322 & 0.5225 & 0.2608 & 0.4276 & 81.07 & 30.78 & 133.83 & 239.06 & 215.35 & HepG2 & Yes \\
\hline 8 & 0.2396 & 0.4608 & 0.2969 & 0.4282 & 45.05 & 65.69 & 13.90 & 114.84 & 24.61 & MCF7 & Yes \\
\hline 9 & 0.3480 & 0.5227 & 0.2816 & 0.4172 & 85.40 & 17.63 & 145.03 & 245.45 & 212.38 & HepG2 & Yes \\
\hline 10 & 0.1922 & 0.4105 & 0.3000 & 0.4317 & 116.68 & 190.13 & 37.48 & 143.30 & 14.28 & MCF10A & Yes \\
\hline 11 & 0.2696 & 0.4923 & 0.2470 & 0.5345 & 45.10 & 186.87 & 130.23 & 419.83 & 277.94 & HeLa & Yes \\
\hline
\end{tabular}




\begin{tabular}{|c|cccc|ccccc|c|c|}
\hline 12 & 0.1762 & 0.4017 & 0.2620 & 0.4397 & 126.70 & 218.81 & 33.14 & 135.54 & 26.79 & MCF10A & Yes \\
\hline 13 & 0.2214 & 0.5123 & 0.2224 & 0.4006 & 142.84 & 85.51 & 76.09 & 67.26 & 115.83 & NT2 & Yes \\
\hline 14 & 0.3043 & 0.5132 & 0.2906 & 0.4188 & 58.34 & 11.56 & 83.82 & 174.45 & 131.09 & HepG2 & Yes \\
\hline 15 & 0.2106 & 0.5060 & 0.2212 & 0.3504 & 249.20 & 125.76 & 128.67 & 19.60 & 120.46 & NT2 & Yes \\
\hline 16 & 0.2500 & 0.4338 & 0.2866 & 0.4370 & 42.57 & 91.48 & 17.77 & 146.41 & 32.76 & MCF7 & Yes \\
\hline 17 & 0.2497 & 0.4385 & 0.3183 & 0.4474 & 37.55 & 101.11 & 27.99 & 187.27 & 38.27 & MCF7 & Yes \\
\hline 18 & 0.3080 & 0.5028 & 0.2490 & 0.4165 & 71.37 & 23.88 & 87.89 & 163.10 & 150.18 & HepG2 & Yes \\
\hline 19 & 0.2014 & 0.5019 & 0.2195 & 0.3703 & 209.34 & 119.94 & 97.24 & 23.23 & 102.24 & NT2 & Yes \\
\hline 20 & 0.2442 & 0.4478 & 0.2962 & 0.4491 & 26.92 & 85.96 & 13.54 & 161.54 & 38.23 & MCF7 & Yes \\
\hline 21 & 0.1984 & 0.4983 & 0.2639 & 0.3990 & 126.22 & 85.84 & 42.84 & 41.87 & 48.20 & NT2 & Yes \\
\hline 22 & 0.2687 & 0.4759 & 0.2955 & 0.5638 & 47.38 & 247.78 & 160.29 & 531.18 & 302.08 & HeLa & Yes \\
\hline 23 & 0.1957 & 0.4665 & 0.3339 & 0.4352 & 77.78 & 119.25 & 25.96 & 133.07 & 13.86 & MCF10A & No \\
\hline 24 & 0.1894 & 0.4063 & 0.2802 & 0.4425 & 105.73 & 196.77 & 29.16 & 148.28 & 22.17 & MCF10A & Yes \\
\hline 25 & 0.2008 & 0.4006 & 0.3083 & 0.4405 & 115.26 & 207.02 & 48.89 & 182.57 & 27.52 & MCF10A & Yes \\
\hline 26 & 0.2829 & 0.4828 & 0.3044 & 0.5300 & 18.49 & 161.97 & 116.83 & 429.81 & 232.76 & HeLa & Yes \\
\hline 27 & 0.2437 & 0.4860 & 0.2171 & 0.4450 & 63.85 & 83.40 & 44.56 & 139.36 & 120.30 & MCF7 & No \\
\hline 28 & 0.2733 & 0.4833 & 0.3009 & 0.5290 & 15.89 & 159.67 & 105.44 & 410.52 & 219.58 & HeLa & Yes \\
\hline 29 & 0.3207 & 0.5218 & 0.2668 & 0.4210 & 77.91 & 21.98 & 116.66 & 206.43 & 185.87 & HepG2 & Yes \\
\hline 30 & 0.3281 & 0.5155 & 0.2974 & 0.4049 & 78.23 & 4.10 & 112.12 & 188.52 & 152.38 & HepG2 & Yes \\
\hline
\end{tabular}

\section{References}

1. Miranda, O. R.; You, C. C.; Phillips, R.; Kim, I. B.; Ghosh, P. S.; Bunz, U. H. F.; Rotello, V. M. J. Am. Chem. Soc. 2007, 129, 9856.

2. Kim, I. B.; Dunkhorst, A.; Gilbert, J.; Bunz, U. H. F. Macromolecules 2005, 38, 4560.

3. You, C. C.; Miranda, O. R.; Gider, B.; Ghosh, P. S.; Kim, I. B.; Erdogan, B.; Krovi, S. A.; Bunz, U. H. F.; Rotello, V. M. Nat. Nanotechnol. 2007, 2, 318.

4. Kim, I. B.; Phillips, R.; Bunz, U. H. F. Macromolecules 2007, 40, 5290.

5. Phillips, R. L.; Miranda, O. R.; You, C. C.; Rotello, V. M.; Bunz, U. H. F. Angew. Chem., Int. Ed. 2008, $47,2590$.

6. Bajaj, A.; Miranda, O. R.; Kim, I.-B.; Phillips, R. L.; Jerry, D. J.; Bunz, U. H. F.; Rotello, V. M. Proc. Natl. Acad. Sci. U. S. A. 2009, 106, 10912. 
7. Medintz, I. L.; Clapp, A. R.; Brunel, F. M.; Tiefenbrunn, T.; Uyeda, H. T.; Chang, E. L.; Deschamps, J. R.; Dawson, P. E.; Mattoussi, H. Nat. Mater. 2006, 5, 581.

8. (a) Clapp, A. R.; Medintz, I. L.; Mauro, J. M.; Fisher, B. R.; Bawendi, M. G.; Mattoussi, H. J. Am. Chem. Soc. 2004, 126, 301. (b) K. Boeneman, B. C. Mei, A. M. Dennis, G. Bao, J. R. Deschamps, H. Mattoussi, I. L. Medintz, J. Am. Chem. Soc. 2009, 131, 3828.

9. Lakowicz, J. R. Principles of Fluorescence Spectroscopy, $2^{\text {nd }}$ Edn., Kluwer Academic/Plenum Publishers, New York 1999.

10. Duan, X.; Liu, L.; Feng, X.; Wang, S. Adv. Mater. 2010, 22, 1602.

11. Phillips, R. L.; Miranda, O. R.; Mortenson, D. E.; Subramani, C.; Rotello, V. M.; Bunz, U. H. F. Soft Matter 2009, 5, 607.

12. SYSTAT11.0, SystatSoftware, Richmond, CA94804, USA, 2004.

13. Mahalanobis, P. C. Proc. Natl. Inst. Sci. India 1936, $2,49$.

14. R Development Core Team (2010). $R$ : A language and environment for statistical computing. $R$ Foundation for Statistical Computing, Vienna, Austria. ISBN 3-900051-07-0, URL http://www.Rproject.org. 